This item was submitted to Loughborough's Research Repository by the author.

Items in Figshare are protected by copyright, with all rights reserved, unless otherwise indicated.

\title{
Recent advances in the production of controllable multiple emulsions using microfabricated devices
}

PLEASE CITE THE PUBLISHED VERSION

http://dx.doi.org/10.1016/j.partic.2015.10.001

\section{PUBLISHER}

Elsevier / @ Chinese Society of Particuology and Institute of Process Engineering, Chinese Academy of Sciences.

\section{VERSION}

AM (Accepted Manuscript)

\section{PUBLISHER STATEMENT}

This work is made available according to the conditions of the Creative Commons Attribution-NonCommercialNoDerivatives 4.0 International (CC BY-NC-ND 4.0) licence. Full details of this licence are available at: https://creativecommons.org/licenses/by-nc-nd/4.0/

\section{LICENCE}

CC BY-NC-ND 4.0

\section{REPOSITORY RECORD}

Vladisavljevic, Goran. 2016. "Recent Advances in the Production of Controllable Multiple Emulsions Using Microfabricated Devices". figshare. https://hdl.handle.net/2134/20022. 


\title{
Recent advances in production of controllable multiple emulsions using microfabricated devices
}

Goran T. Vladisavljević

Chemical Engineering Department, Loughborough University, Loughborough, Leicestershire, LE11 3TU, United Kingdom. e-mail: G.Vladisavljevic@lboro.ac.uk. Phone: (+44) (0)1509 222518

Keywords: membrane emulsification; microchannel emulsification; drop microfluidics; microencapsulation; multiple emulsions; Janus droplets.

\begin{abstract}
This review focuses on recent developments in fabrication of multiple emulsions in microscale systems, such as membrane, microchannel array and microfluidic emulsification devices. Membrane and microchannel emulsification offer great potential in manufacturing multiple emulsions with uniform drop sizes and high encapsulation efficiency of encapsulated actives. Microfluidic devices enable unprecedented level of control over the number, size and type of internal droplets at each hierarchical level but suffer from low production scales. Microfluidic methods can be exploited to generate high-order multiple emulsions (triple, quadruple and quintuple), non-spherical (discoidal and rod-like) drops and drops with asymmetric properties such as Janus and ternary drops, composed of two or three distinct regions on the surface. Multiple emulsion droplets generated in microfabricated devices can be used as templates for vesicles (polymersomes, liposomes, colloidosomes) with multiple inner compartments for simultaneous encapsulation and release of incompatible actives or reactants.
\end{abstract}




\section{Introduction}

A multiple (double or duplex) emulsion is an emulsion in an emulsion (Garti, 1997). Conventional multiple emulsions consist of numerous drops of inner phase dispersed within larger drops of middle phase, which are themselves dispersed in an outer phase (Figure 1a). The middle phase must be immiscible with both the inner and outer phase. Two main types of multiple emulsions are water-in-oil-in-water $\left(\mathrm{W}_{1} / \mathrm{O} / \mathrm{W}_{2}\right)$ and oil-in-water-in-oil $\left(\mathrm{O}_{1} / \mathrm{W} / \mathrm{O}_{2}\right)$. A $\mathrm{W}_{1} / \mathrm{O} / \mathrm{W}_{2}$ emulsion consists of drops of the inner water phase $\mathrm{W}_{1}$ dispersed within oil drops, which are then dispersed in the outer water phase $\mathrm{W}_{2}$. In an $\mathrm{O}_{1} / \mathrm{W} / \mathrm{O}_{2}$ emulsion, water drops enclosing smaller droplets of the oil phase $\mathrm{O}_{1}$ are dispersed in the outer oil phase $\mathrm{O}_{2}$. Multiple emulsions are used to encapsulate actives in the food, cosmetic and pharmaceutical industry, in separation processes, and synthesis of microcapsules (Vladisavljević et al., 2005a). Other types of multiple emulsions have also been prepared, such as oil-in-water-in-water $\left(\mathrm{O} / \mathrm{W}_{1} / \mathrm{W}_{2}\right)$ (Kim et al., 2006) and ethanol-in-oil-in-water (E/O/W) (Nakajima et al., 2003).

Microfluidic emulsification allows precise fabrication of structured multiple emulsions with controlled drop morphology (Figures 1b-i). Core-shell drops consist of a single drop of the inner phase coated by a thin layer of the middle phase (Figure 1b). High-order multiple emulsions contain nested drops with concentric anion-like liquid shells around the core drop (Figure 1c). Depending of the number of phases within each multiple emulsion drop, highorder multiple emulsions can be divided into triple $\left(\mathrm{W}_{1} / \mathrm{O}_{2} / \mathrm{W}_{3} / \mathrm{O}_{4}\right.$ or $\left.\mathrm{O}_{1} / \mathrm{W}_{2} / \mathrm{O}_{3} / \mathrm{W}_{4}\right)$, quadruple $\left(\mathrm{W}_{1} / \mathrm{O}_{2} / \mathrm{W}_{3} / \mathrm{O}_{4} / \mathrm{W}_{5}\right.$ or $\left.\mathrm{O}_{1} / \mathrm{W}_{2} / \mathrm{O}_{3} / \mathrm{W}_{4} / \mathrm{O}_{5}\right)$, and quintuple $\left(\mathrm{W}_{1} / \mathrm{O}_{2} / \mathrm{W}_{3} / \mathrm{O}_{4} / \mathrm{W}_{5} / \mathrm{O}_{6}\right.$ or $\mathrm{O}_{1} / \mathrm{W}_{2} / \mathrm{O}_{3} / \mathrm{W}_{4} / \mathrm{O}_{5} / \mathrm{W}_{6}$ ), consisting of 3 , 4, and 5 phases respectively, incorporated within each complex drop (Abate \& Weitz, 2009). Multiple emulsion drops of high order are useful in the production of complex capsules for co-encapsulation and simultaneous or sequential release of multi-component actives (Kim \& Weitz, 2011). 
Multiple emulsion drops shown in Figure 1d consist of the controlled number of small inner drops encapsulated within each large drop. Typically, the number of inner drops can range from 1 to 7 (Chu et al., 2007). Each inner drop can contain a controlled number of even smaller drops and the size and number of drops at each hierarchical level can be adjusted independently (Chu et al., 2007). Figure 1e shows triple emulsion drops consisting of 4 innermost drops in each middle drop and 3 middle phase drops in each outer drop. The inner drops can be additionally separated from the outermost phase by a shell (Figure 1f) that can be solidified and ruptured in response to an external stimulus, such as $\mathrm{pH}$ or temperature, to achieve a burst release of inner drops (Chu et al., 2007; Liu et al., 2010). Figure 1g shows multiple emulsion drops containing distinct inner drops encapsulated within the same outer drop. The number of inner drops of the same kind can be precisely controlled by microfluidic methods (Wang et al., 2011). Janus drops are composed of two hemispheres with various physical and chemical properties. Strictly speaking, a Janus drop should have two distinct regions on the surface of roughly equal surface area. However, the term has been expanded to include all multi-segment droplet structures with regions of different composition co-existing in asymmetric geometries (Yang et al., 2012) (Figure 1h).

In the absence of external forces, liquid drops take a spherical shape due to interfacial tension that favours the form with a minimum surface area for a given volume. Non-spherical drops (rods, discoids, ellipsoids, etc) (Figure 1i) can be produced in confined (shallow or narrow) microfluidic channels (Xu et al., 2005).

In the subsequent sections, the production of each of the above mentioned compound droplet structures will be reviewed. The main emphasis will be put on the fabrication routes, although some applications of these emulsions will be also discussed, especially as precursors of structured solid particles. 


\section{Micro-scale emulsification methods}

The microfabrication methods discussed in this paper are presented in Figure 2. The generation of drops in microfluidic devices typically involves injection of one liquid (the dispersed phase) through a single microchannel (MC) into another perpendicular MC carrying the continuous phase (T junction) (Thorsen et al., 2001) or break-up of coaxial streams of immiscible liquids in a narrow orifice (flow focusing method) (Anna et al., 2003). The droplets generated in microfluidic devices are highly uniform in size, with a variation of their sizes in the dripping regime of less than $3 \%$ and the drop generation frequency is $10^{2}-10^{4} \mathrm{~Hz}$. The volume flow rate of the dispersed phase is only $0.01-10 \mathrm{ml} \mathrm{h}^{-1}$, because there is typically only one inlet MC for delivery of the dispersed phase and thus only one droplet generation unit (DGU). In contrast, membrane and MC array plates have a large number of pores or parallel MCs that can be regarded as massively parallel T-junctions.

Membrane devices generate droplets by injecting the dispersed phase or coarsely emulsified mixture of the dispersed and continuous phase through a microporous membrane. In direct membrane emulsification (DME), a pure dispersed phase is injected through the membrane, whereas in premix membrane emulsification (PME) a coarsely emulsified mixture passes through the membrane (Vladisavljević et al, 2004). In PME, the volume flow rate of the dispersed phase can reach $10^{4} \mathrm{ml} \mathrm{h}^{-1}$ through the cross-sectional area of the membrane of less than $4 \mathrm{~cm}^{2}$ (Vladisavljević et al., 2004) and the variation of drop sizes is 10-20 \%. In MC array devices, the dispersed phase is injected through arrays of parallel MCs with step structures (Kawakatsu et al., 2007). The volume flow rate of the dispersed phase can exceed $10^{3} \mathrm{ml} \mathrm{h}^{-1}$ with the variation of drop sizes is-of less than 5\% (Kobayashi et al., 2012). The droplets shown in Figs. 1 (b-i) can only be formed in microfluidic devices that have at least three different inlet MCs for the inner, middle, and outer phase. Currently, membrane and MC 
emulsification devices only have two inlets and can only be used for the secondary emulsification step in the production of multiple emulsions shown in Fig. 1a.

\section{Multiple emulsions with numerous inner drops (Figure 1a)}

$\mathrm{W}_{1} / \mathrm{O} / \mathrm{W}_{2}$ emulsions with numerous inner drops are conventionally prepared in a twostep emulsification process using two different types of surfactants: a hydrophobic surfactant with a low hydrophilic-lipophilic balance (HLB) value which is added to the oil phase to stabilise inner drops against coalescence and a hydrophilic surfactant with a high HLB value which is dissolved in the outer aqueous phase to stabilise outer drops. The primary $\mathrm{W}_{1} / \mathrm{O}$ emulsion is prepared under high shear conditions in order to generate the smallest possible inner drops, as such drops are more stable during the subsequent emulsification step and can be incorporated more effectively efficiently within the outer drops (Pawlik et al., 2013). The secondary emulsification is carried out under mild shear conditions to minimise the release of inner drops into the continuous phase. In traditional emulsification devices, high shear rates are applied, ranging from $\sim 10^{5} \mathrm{~s}^{-1}$ in high-shear mixers and colloid mills to $10^{7} \mathrm{~s}^{-1}$ in the Microfluidizer $^{\circledR}$ (Vladisavljević et al., 2015). However, external flow (shear) causes internal streaming in drops, which increases the frequency of collision (and thus coalescence) of internal drops in the middle phase (Van der Graaf et al., 2005). Also, elongation of drops under high shear stress stretches the middle phase and increases the interfacial area available for the release of inner drops. Thus, only low to moderate shear must be used in the secondary emulsification step to obtain high encapsulation yield of inner drops, which inevitable leads to high polydispersity of outer drops.

\subsection{Membrane emulsification}


Membrane emulsification (ME) allows both a low size polydispersity of outer drops and high encapsulation yield of inner drops, since uniform drops can be formed even under quiescent conditions (Kukizaki, 2009a). The process was recently reviewed by Spyropoulos et al. (2014), Schroën et al. (2012), and Piacentini et al. (2014).

The common membranes used in the process are Shirasu Porous Glass (SPG) (Vladisavljević et al., 2005b), micro-engineered (Kosvintsev et al., 2005, Nazir et al., 2013), and polymeric (Yafei et al., 2006). Hydrophilic membranes are needed for preparation of $\mathrm{W}_{1} / \mathrm{O} / \mathrm{W}_{2}$ emulsions and hydrophobic membranes are used for $\mathrm{O}_{1} / \mathrm{W} / \mathrm{O}_{2}$ emulsions. A primary submicron emulsion is usually prepared by microfluidization, sonication or high-shear mixing and ME is used for the secondary emulsification step. The concentration of inner phase is typically between 30 and 50 vol\% and the membrane pore size must be no less than twice the diameter of the internal drops (Mine et al., 1996).

The examples of $\mathrm{W}_{1} / \mathrm{O} / \mathrm{W}_{2}$ emulsions prepared using $\mathrm{ME}$ are given in Table 1 . In most cases, the inner water phase contains a hydrophilic active ingredient, such as anticancer drug (epirubicin, irinotecan), biological actives (vitamins, enzymes, polyphenols, hormones) or marker substances (salts, fluorescent dyes), whose concentration in the continuous phase can be measured accurately to estimate the entrapment efficiency in the process. A leakage of active ingredient can be reduced by solidifying middle phase, for instance, by spray drying (Berendsen et al., 2015), evaporation of organic solvent from middle phase (Ma et al., 2013) or melt cooling (Kukizaki \& Goto, 2007). Alternatively, internal drops can be converted into surfactant-coated nanocrystals of active ingredient by internal water evaporation (Kukizaki, 2009b), turned into a gel (Surh et al., 2007) or transformed into nanoparticles by in-situ chemical reaction within internal drops (Yang et al., 2010).

Different ME methods for production of multiple emulsions are shown in Fig. 3. In batch cross-flow ME (Fig. 3a), the $\mathrm{W}_{2}$ phase circulates in a closed loop through the membrane 
tube using a low shear pump, such as a screw pump (Vladisavljević et al., 2002). The $\mathrm{W}_{1} / \mathrm{O}$ phase penetrates through the pores from outside to inside the membrane tube until the volume fraction of the outer phase $\left(\phi_{2}\right)$ reaches the target value. In continuous cross-flow ME, the $\mathrm{W}_{2}$ phase flows slowly through the membrane module in single pass and the additional shear on the membrane surface is generated by swirl flow (Shimoda et al., 2011) or back-and-forward pulsations of the continuous phase flow (Holdich et al., 2013, Piacentini et al., 2013). In stirred cell ME (Fig. 3b), the $\mathrm{W}_{1} / \mathrm{O}$ emulsion is injected into the agitated $\mathrm{W}_{2}$ phase through a flat membrane fitted at the bottom of the cell (Dragosavac et al., 2012) or through a tubular membrane immersed into the continuous phase (Kukizaki \& Goto, 2007). In oscillating ME (Fig. 3c), tubular vertical membrane moves within a static continuous phase periodically clockwise and counter-clockwise (Silva et al., 2015) or upward and downward (Holdich et al., 2010) with frequencies from 10 to $90 \mathrm{~Hz}$ and amplitudes from 0.1 to $7 \mathrm{~mm}$ to generate shear on the membrane surface. In rotating (spinning) ME systems, a tubular membrane rotates within a static continuous phase at the speeds ranging from 100-1500 rpm in laboratory systems (Pawlik et al., 2012; Yuan et al., 2009; Vladisavljević et al., 2006a; Aryanti et al., 2006) to 6000-10000 rpm in commercial MEGATRON ${ }^{\circledR}$ devices (Graber et al., 2010). $\mathrm{O}_{1} / \mathrm{W} / \mathrm{O}_{2}$ emulsions can be produced using the same methods, but an $\mathrm{O}_{1} / \mathrm{W}$ emulsion must be injected through a hydrophobic membrane into the $\mathrm{O}_{2}$ phase.

In premix ME (PME, Fig. 3d), a crude multiple emulsion (the 'premix') is forced through the membrane once or repeatedly, resulting in the disruption of pre-formed droplets in the pores and the formation of smaller and more uniform drops (Vladisavljević et al., 2004; 2006b). PME requires the higher transmembrane pressures than DME, leading to the higher permeation rates through the membrane and the smaller drop sizes. On the other hand, PME is more prone to membrane fouling and the drops are more polydisperse. The typical SPG micro kit for PME is shown in Fig. 4. A pressurised premix from the pressure vessel rapidly 
penetrates through the membrane tube from outside to inside. The operating pressure can range from 1-3 bar (for the 10- $\mu \mathrm{m}$ membrane) to more than 10 bar (for the 1- $\mu \mathrm{m}$ membrane) and up to 50 bar for submicron pore sizes. The encapsulation efficiency of the marker in the product $\mathrm{W}_{1} / \mathrm{O} / \mathrm{W}_{2}$ emulsion after 5 passes through the membrane with a pore size of $10.7 \mu \mathrm{m}$ was $83-85 \%$, the transmembrane flux exceeded $20 \mathrm{~m}^{3} \mathrm{~m}^{-2} \mathrm{~h}^{-1}$ and the size of the $\mathrm{W}_{1} / \mathrm{O}$ drops was 4-9 $\mu \mathrm{m}$ (Vladisavljević et al., 2006b).

\subsection{Microchannel emulsification}

Multiple emulsions with monodisperse outer drops can be produced using 3D parallel MC arrays fabricated on a single crystal silicon substrate. In the grooved-type MC plate (Kawakatsu et al., 1997; Vladisavljević et al., 2012b), parallel MCs are fabricated along the surface of the plate by anisotropic wet etching and situated on long terraces (Fig. 5a). The $\mathrm{W}_{1} / \mathrm{O}$ phase supplied from the central hole is forced through MCs into the $\mathrm{W}_{2}$ phase (Kawakatsu et al., 2001; Sugiura et al., 2004). After emerging from the MCs, the dispersed phase is squeezed between the terrace and the cover glass and grows in the form of expanding disks on the terrace. When the dispersed phase reaches the deeper part downstream of the terrace called the well, a small spherical droplet starts to grow from the edge of the disk into the well. Once the droplet reaches a certain size, the interfacial tension pinches the dispersed phase into drops, which is known as "spontaneous droplet formation” (Sugiura et al., 2002). Kawakatsu et al. (2001) produced $\mathrm{W}_{1} / \mathrm{O} / \mathrm{W}_{2}$ emulsions with a size polydispersity of outer drops of 5-8 \% using the middle phase consisting of $5 \mathrm{wt} \%$ TGPR in decane or ethyl oleate. Larger and more polydisperse drops were formed when more viscous oil was used. Internal droplets larger than the MCs passed through and were disrupted into smaller drops without bursting the middle phase film. As a result, the entrapment efficiency of a low-molecular weight fluorescent dye (calcein) was 91 \% (Sugiura et al., 2004). 
Grooved MC plates can accommodate less than 5 MCs per $1 \mathrm{~mm}^{2}$, since the MCs are placed in longitudinal direction and the feed channels for the continuous and dispersed phase must be provided onto the plate surface. In the straight-through plate (Fig. 5b), MCs are fabricated across the plate (laterally), from one side to another, by deep reactive ion etching (DRIE). The distribution channels are placed above and beneath the MC plate, leading to more efficient space utilization than in the grooved-type design. For instance, a grooved 60×60 mm MC plate can accommodate 12,000 MCs (3.3 MCs per $1 \mathrm{~mm}^{2}$ ) with a depth of 2 $\mu \mathrm{m}$ and a width of $10 \mu \mathrm{m}$ (Kobayashi et al., 2010). On the other hand, a straight-through 40×40 mm MC plate can contain more than 210,000 MCs (more than 130 MCs per $1 \mathrm{~mm}^{2}$ ) resulting in much higher drop throughputs (Kobayashi et al., 2005b). Rectangular straightthrough MCs provide better performance than circular MCs due to instability imposed by the elongated interface (Kobayashi et al., 2002), but the ratio of channel length to channel width must be 3 or above (Kobayashi et al. 2004; van Dijke et al., 2010). Asymmetric MC plates are fabricated with circular MCs on the upstream part and rectangular MCs on the downstream part (Kobayashi et al., 2005c; Vladisavljević et al., 2011). In asymmetric MC plates, emerging drops do not occupy the entire width of the MC (Fig. 5c) and thus, the continuous phase can flow inside the MC during pinch-off, which promotes the drop detachment. Fig. 5d shows monodisperse $\mathrm{W}_{1} / \mathrm{O} / \mathrm{W}_{2}$ drops produced using asymmetric straight-through MCs.

\section{Core-shell drops (Figure 1b)}

\subsection{Production of core-shell drops in microfluidic junctions}

Microfluidic devices can generate core-shell drops in a single step or using two consecutive emulsification steps, allowing precise control over the size of the drops in each step. T-junction is the simplest microfluidic structure for making drops (Thorsen et al., 2001). The dispersed phase is injected into the continuous phase through the inlet channel, which is 
perpendicular to the main channel carrying the continuous phase. The two liquids meet at the junction where the shear stress generated by the continuous phase and the evolution of the pressure upstream of the emerging drop causes the dispersed phase to distort in the downstream direction and forms a neck that periodically breaks up into drops (Garstecki et al., 2006). Hydrophilic walls of the junction are required to produce O/W emulsions, whereas hydrophobic walls are required for W/O emulsions. Core-shell drops can be made using two chips connected in series, as illustrated in Fig. 6. The internal aqueous drops are produced in the first chip using a hydrophobic T-junction and transferred to the second chip containing the larger hydrophilic T-junction, where each aqueous drop is enclosed in an oil drop (Nisisako, 2005). The process is more reproducible if both T-junctions are fabricated on the same chip.

Okushima et al. (2004) produced core-shell drops using two sequential T-junctions with alternating surface wettability (hydrophilic and hydrophobic) fabricated on the same Pyrex glass chip (Figure 7a-b and Table 2). Internal aqueous drops $\left(\mathrm{d}_{\mathrm{i}}=52 \mu \mathrm{m}, \mathrm{CV}=2.7 \%\right)$ were formed at the upstream hydrophobic junction (60 $\mu \mathrm{m}$ width $\times 25 \mu \mathrm{m}$ depth) and transferred to the downstream hydrophilic junction (130 $\mu \mathrm{m}$ width $\times 65 \mu \mathrm{m}$ depth), while maintaining the constant drop spacing in the oil stream. Oil drops $\left(\mathrm{d}_{\mathrm{o}}=83 \mu \mathrm{m}, \mathrm{CV}=2.8 \%\right)$ were formed at the downstream junction. The upstream junction was coated with a non-polar silane to render the glass surface hydrophobic. The frequency of drop generation at both junctions was equal $\left(22 \mathrm{~Hz}\right.$ ) ensuring that exactly one aqueous drop was enclosed in each oil drop. $\mathrm{O}_{1} / \mathrm{W} / \mathrm{O}_{2}$ emulsions were generated using the same chip design, but with a hydrophilic upstream junction and a hydrophobic downstream junction.

Core-shell drops were also produced using two serial cross junctions with alternating wettability (Figs. 7c-e) fabricated in polydimethylsiloxane (PDMS) by soft lithography (Bauer et al., 2010; Abate et al., 2011). The inner phase is injected into the central inlet and the middle and outer phase into separate side inlets. Although the middle and outer phase are 
injected into the main channel from two opposite sides, only one inlet port is used for each phase, since their inlet streams are split into two streams at the upstream T-junctions before their delivery to side channels (Fig. 6e). Two sequential hydrophobic cross-junctions with different depths of the main channel were used to produce core-shell drops with an ultra-thin ( $<1 \mu \mathrm{m})$ oil shell surrounding a water core (Saeki et al., 2010a; 2010b).

When two serial cross-junctions are used to generate core-shell drops, break-up events normally occur in both junctions, leading to a two-step drop formation process (Fig. 7d): the inner drop is formed in the first cross-junction and then enclosed in the outer drop in the second. The first break-up event can be removed by increasing the flow rate of the inner fluid (Abate et al., 2011). In one-step drop formation process, a jet of the inner phase does not break in the first junction but extends into the second junction, where it is surrounded by a layer of middle phase, producing a coaxial jet. If the flow rates in the second junction are set to induce a dripping instability, the coaxial jet is pinched into core-shell drops, as illustrated in Fig. 7c. One-step drop formation is preferred, since it avoids the difficulty of matching the break-up rates of different junctions, which improves drop uniformity. In addition, one-step process can create very thin shells and enable difficult fluids that do not easily break into drops, like viscoelastic fluids, to be emulsified controllably (Abate et al., 2011). By integrating 15 double cross junction in a planar array, core/shell droplets were produced at the flow rates of the core and shell phase of 24 and $30 \mathrm{ml} \mathrm{h}^{-1}$, respectively, and both inner and outer diameter variation was below 6\% (Romanowsky et al., 2012; Vladisavljević et al., 2013).

\subsection{Production of core-shell drops in non-planar PDMS devices}

In a planar (two-dimensional) microfluidic junction, an emerging drop wets the walls of the main channel, because the inlet channel is usually of the same depth as the main channel, which can significantly compromise the drop generation process and lead to damage of the 
core-shell structure. In addition, in planar microfluidic devices all channels are rectangular, which additionally prevents the continuous phase from engulfing fully the dispersed phase during drop generation. Takeuchi et al. (2005) developed an axisymmetric (3D) flow focusing device for making core-shell drops in which a coaxial jet composed of the dispersed and middle phase is completely separated from the walls by the continuous phase due to circular cross section of the orifice, as illustrated in Fig. 8a. The device was fabricated in PDMS using insulated optical fibre as a master for circular channel. A short section of the insulation was removed using a scalpel to expose the bare fibre in the central region. This fibre was molded in PDMS, and after curing, removed from the PDMS block to leave the circular channel with a narrow section in the middle that will serve as a flow-focusing orifice. An inlet for the dispersed phase and an outlet for the product emulsion were formed by inserting round glass capillaries into the channel on both sides. Since the device was fabricated from a single piece of PDMS, rather than by bonding two parts together, it does not leak at higher fluid flow rates and pressures. However, these devices are non-reproducible as they are handmade.

Reproducible non-planar flow focusing devices were fabricated by soft lithography using two complementary 3D master molds, one for the bottom part of the junction and a second for the top part (Rotem et al., 2012; Chang \& Su, 2008). The master molds were fabricated via a two-step photolithography on a silicon wafer. After replicating the top and bottom molds in PDMS, the two replicas were aligned and bonded face to face (Fig. 8b). Core-shell drops can be produced in non-planar microfluidic junctions without the need to locally modify the wettability of the channel walls. Rotem et al. (2012) produced water-in-oil core-shell drops using two hydrophobic junctions shown in Fig. 8b. Hydrophobic walls are favourable for making water drops in oil, and hence a conventional planar junction was used for the first emulsification step. To produce double emulsions, water drops and the surrounding oil were emulsified at the second junction, which required a non-planar geometry 
due to its hydrophobic walls. In non-planar junctions, the inlet channel for the dispersed phase has a smaller cross sectional area than the collection channel, enabling the continuous phase to fully surround the dispersed phase and de-wet it from the walls. As a result, the oil drops are formed even though the channels are hydrophobic and favours the oil phase. By contrast, when using a planar geometry in the second junction, the middle oil phase wetted the walls even at high flow rates of the continuous water phase, and the formation of double emulsions was not possible. The device can produce oil-in-water core-shell drops by using a non-planar geometry for the first junction and planar geometry for the second junction (Rotem et al., 2012).

\subsection{Production of core-shell drops in glass capillary devices}

PDMS channels swell in organic solvents and tend to deform under pressure due to their high elasticity. Glass is more chemically inert than PDMS and can easily be functionalized to control its wetting properties. A treatment with octadecyltrimethoxysilane will make the glass surface hydrophobic, whereas a treatment with 2-[methoxy(polyethyleneoxy)propyl]trimethoxysilane will enhance the surface hydrophilicity. Glass capillary microfluidic devices are 3D devices consisting of coaxial assemblies of borosilicate glass capillaries attached onto the surface of a microscope glass slide (Utada et al., 2005; 2007). Multiple emulsions with numerous inner drops can be produced in two-phase glass capillary devices, such as co-flow device and countercurrent flow focusing device (Vladisavljević et al., 2014b).

A three-phase glass capillary device can be used to make core/shell drops (Fig. 9a). It consists of two tapered round capillaries inserted into the opposite ends of a square capillary. The inner dimension of the square capillary is only slightly larger than the outer diameter of the round capillaries for easy coaxial alignment of the round capillaries. The inlet fluids are supplied via hypodermic needles with plastic hubs attached to the capillaries. Alternatively, 
custom-made plastic connectors fabricated by 3D printing (Martino et al., 2014) or commercially available components (Benson et al., 2013) can be used to hold the capillaries in position and provide entry ports for the inlet fluids. The benefits of these connectors are that the device can be disassembled, cleaned, and reassembled, and the distance between the injection and collection capillary can be changed during operation.

The inner phase is pumped through the left round capillary, while the middle phase is injected in the same direction through the interstitial space formed between the left round capillary and the square capillary. The outer phase is injected from the opposite side through the interstitial space formed between the right round capillary and the square capillary. The three fluids become hydrodynamically focused at the tapered section of the right round capillary, which results in the break-up of coaxial jet of inner and middle phase and formation of core/shell drops inside the collection capillary. At low flow rates, drops are formed within one orifice diameter of the inlet section through the dripping mechanism. The jet pinch-off in dripping regime is facilitated by a vortex flow at the upstream end of the neck (Nabavi et al., 2015a). In the narrowing jetting regime, no vortex flow was observed and the jet pinch-off occurrs due to high velocity at the downstream end of the neck compared to that at the upstream end. Typical orifice diameters of the injection tube are 10-50 $\mu \mathrm{m}$ and those of the collection tube are 50-400 $\mu \mathrm{m}$. The drop size and shell thickness can be precisely tuned by adjusting the orifice diameters, the flow rates and physical properties of all fluids and the distance between the inner capillaries (Nabavi et al., 2015b).

The shell material can be polymerised or cross-linked to produce a solid shell around the inner drop (Kim et al., 2007; Liu et al., 2010; Ye et al., 2010; Kanai et al., 2010; Nie et al., 2005). Polymer capsules with liquid cores have applications in the encapsulation of drugs, cells, pesticides, perfumes, liquid inks, paints, toners, solvents, and reactive liquid chemicals (Peyratout \& Dähne, 2004; Vericella et al., 2015; Chen et al., 2014). The middle phase may 
also contain dissolved particles or amphiphilic molecules such as phospholipids or diblock copolymers, which can undergo self-assembly at two concentric oil/water interfaces upon solvent evaporation, which can lead to the formation of vesicles such as giant liposomes (Shum et al., 2008), polymersomes (Lorenceau et al., 2005) and colloidosomes (Lee \& Weitz, 2008) (Table 2). Moreover, core-shell templating is a useful tool for generation of uniform single emulsion droplets from highly viscous ( $\approx 100$ cP) liquids (Josephides \& Sajjadi, 2015) and hole/shell microparticles (Wang et al., 2013).

Typical shell thicknesses in the device shown in Fig. 9a are from several microns to more than $100 \mu \mathrm{m}$. Forming ultra-thin shells with thicknesses below $1 \mu \mathrm{m}$ is challenging, because it requires extremely low flow rates of the middle phase, which can be difficult to achieve with a syringe pump. To overcome this limitation, a modified device was constructed consisting of two coaxial injection capillaries and one collection capillary inserted within a square capillary (Fig. 9b). The middle phase is injected through larger round capillary and the inner phase is injected through smaller round capillary. To make W/O/W emulsion drops, the inner wall of the larger capillary must be hydrophobic to prevent wetting of the aqueous phase. Under these conditions, the inner aqueous phase forms a stable jet within the larger capillary, which is separated from the wall by a very thin layer of the middle oil phase. The outer phase is supplied from the left, through the interstitial space formed between the square and the round injection capillaries. The three fluids flow into the orifice of the collection capillary and form core/shell drops with ultra-thin shells. An ultra-thin middle layer provides enhanced stability compared to thick shells (Datta et al., 2014). If the shell is solidified by solvent evaporation, its thickness can be as small as a few tens of nanometres (Kim et al., 2011a).

\section{Drops with multiple concentric shells (Figure 1c)}


Microfluidic approach shown in Fig. 7d based on linear arrays of PDMS cross junctions with alternating wettability can be extended to three or more cross-junctions in series, which can lead to the production of higher-order multiple emulsions, such as triple, quadruple, and quintuple emulsions (Abate \& Weitz, 2009). The size of each outlet nozzle is slightly smaller than the size of incoming drops from the previous junction, which allows the incoming drops to obstruct the nozzle and trigger the formation of the outer drop in the subsequent junction. This hydrodynamic coupling of the junctions synchronizes the drop formation such that the multiple emulsion formation is stable. A triple $\mathrm{W}_{1} / \mathrm{O}_{2} / \mathrm{W}_{3} / \mathrm{O}_{4}$ emulsion was formed in the device consisting of three junctions (Fig. 10a) by alternately injecting fluorocarbon oil and water phases into the four inlets. The diameters of the nested inner drops and the outer drop were 30,50 , and $70 \mu \mathrm{m}$, respectively, and the size polydispersity was $\sim 2 \%$ for all of the drops (Abate \& Weitz, 2009).

A high-throughput production of triple $\mathrm{O}_{1} / \mathrm{O}_{2} / \mathrm{O}_{3} / \mathrm{W}_{4}$ emulsion at $\mathrm{Q}_{1}=5.0 \mathrm{ml} \mathrm{h}^{-1}, \mathrm{Q}_{2}=$ $6.0 \mathrm{ml} \mathrm{h}^{-1}, \mathrm{Q}_{3}=20.0 \mathrm{ml} \mathrm{h}^{-1}$, and $\mathrm{Q}_{4}=90.0 \mathrm{ml} \mathrm{h}^{-1}$ was achieved in a glass chip fabricated by DRIE (Nisisako et al., 2012). The chip was consisted of 32 sets of three consecutive cross junctions with a uniform channel depth of $200 \mu \mathrm{m}$ (Fig. 10b). Each of the input holes on the same circle is accessible from a single connector mounted on the side of the module and there are 4 concentric circles to deliver four phases involved in the process.

Sequential (multi-step) emulsification using a series of single drop generation units requires a delicate control of flow rates to synchronize the frequencies of drop generations in all drop generation units, since otherwise triple emulsion would not be formed. Utada et al. (2005) formed triple $\mathrm{W}_{1} / \mathrm{O}_{2} / \mathrm{W}_{3} / \mathrm{O}_{4}$ emulsions, such as water/silicon-oil/water/silicon-oil and water/toluene/water/silicon-oil by single-step emulsification in a glass capillary device (Fig. 11a). The innermost phase $\mathrm{W}_{1}$ was pumped from the inner injection capillary with hydrophobic walls, the inner oil phase $\mathrm{O}_{2}$ was pumped through the outer injection capillary 
with hydrophilic walls, and the aqueous phase $\mathrm{W}_{3}$ was injected from the same direction through the interstitial space between the outer injection capillary and the square capillary. The continuous oil phase $\mathrm{O}_{4}$ was injected from the opposite side through the interstitial space between the square capillary and the collection capillary. All fluids were forced through a cylindrical orifice with hydrophobic walls, resulting in hydrodynamic focusing of the threephase coaxial jet and the formation of triple emulsion.

Triple emulsions can serve as templates of core/shell capsules consisting of one core liquid and two concentric shells. These capsules can be prepared by putting two different types of surface active molecules in each of the intermediate (middle) phases and evaporating them. The example of such two-layer capsule is an asymmetric lipid vesicle, whose inner leaflet was made of POPC (1-Palmitoyl-2-Oleoyl-sn-Glycero-3-Phosphocholine) and the outer leaflet was made of POPS (1-Palmitoyl-2-Oleoyl-sn-Glycero-3-Phospho-L-Serine), or vice versa (Pautot et al., 2003).

Kim \& Weitz (2011) formed triple $\mathrm{W}_{1} / \mathrm{O}_{2} / \mathrm{W}_{3} / \mathrm{O}_{4}$ emulsions in a glass capillary device via confined two-phase flow of immiscible fluids through a single channel (Fig. 11b). The device consists of two tapered hydrophobic cylindrical capillaries inserted into a hydrophilic square capillary, the inner dimension of which is slightly larger than the outer diameter of the cylindrical capillaries. In addition, a small tapered capillary is inserted into the space between the collection and the square capillaries to simultaneously inject a second immiscible phase in the interstitial space, as shown in the cross section of C-C in Fig. 11b. The innermost phase $\mathrm{W}_{2}$ is injected through the cylindrical injection capillary and the oil phase $\mathrm{O}_{2}$ is injected into the space between the injection and the square capillaries from the same direction. The aqueous phase $\mathrm{W}_{3}$ and the oil phase $\mathrm{O}_{4}$ are simultaneously injected into the space between the cylindrical collection capillary and the square capillary, with the oil being injected through the small additional capillary. The surface properties of the walls favours the oil phase flow along 
the outer surface of the collection capillary, while the aqueous phase forms a thin layer onto the inner surface of the square capillary. A strong confinement of the liquids in the interstitial space prevents the Rayleigh-Plateau instability and the breakup of two-phase jet into drops. Four immiscible fluids are simultaneously introduced into the orifice in the form of a coaxial flow, which results in the formation of triple emulsion drops.

The diameter of the middle $\left(D_{2}\right)$ and outer shells $\left(D_{3}\right)$ can be calculated from the diameter of the innermost drops $\left(\mathrm{D}_{1}\right)$ and the fluid flow rates using mass balance equations:

$$
D_{2}=D_{1}\left(1+\frac{Q_{2}}{Q_{1}}\right)^{1 / 3} \quad \text { and } \quad D_{3}=D_{1}\left(1+\frac{Q_{2}+Q_{3}}{Q_{1}}\right)^{1 / 3}
$$

where $\mathrm{Q}_{1}, \mathrm{Q}_{2}$, and $\mathrm{Q}_{3}$ are volumetric flow rates of $\mathrm{W}_{1}, \mathrm{O}_{2}$, and $\mathrm{W}_{3}$ phases, respectively. The opposite wettability of the tube walls (hydrophilic cylindrical capillaries and hydrophobic square capillary) enables preparation of $\mathrm{O}_{1} / \mathrm{W}_{2} / \mathrm{O}_{3} / \mathrm{W}_{4}$ triple emulsion.

$\mathrm{W}_{1} / \mathrm{O}_{2} / \mathrm{W}_{3} / \mathrm{O}_{4} / \mathrm{W}_{5}$ quadruple emulsion can be prepared using a glass capillary device of the same geometry but with different surface properties of the capillaries: the walls of the injection capillary and the collection side of the square capillary are hydrophobic, whereas the collection capillary and the injection side of the square capillary are hydrophilic. As shown in Fig. 11c, two biphasic streams, coming from the opposite sides of the square capillary, form three coaxial interfaces which sequentially break up from the inner to the outer interfaces to form quadruple emulsion drops.

\section{Multiple emulsion drops with controlled number of inner drops (Figure 1d)}

Multiple emulsion drops containing two or more inner droplets can be used as templates for preparation of nonspherical polymersomes (Shum et al., 2011; Kim et al., 2011b) and colloidosomes (Lee \& Weitz, 2009) with multiple inner compartments. Two T-junction drop makers with alternating surface wettability shown in Fig. 7a can be used to produce multiple emulsions with a controlled number of internal droplets within each middle phase drop 
(Nisisako et al., 2005). For generation of monodispersed emulsions, the operating conditions must be adjusted to satisfy the following equation: $f_{1} / f_{2}=N$, where $f_{1}$ and $f_{2}$ are the frequency of drop generation at the first and second junction, respectively, and $\mathrm{N}$ is a positive integer (1, 2, 3...). For core/shell drops $N=1$. By increasing the flow rate of the middle phase at constant flow rates of the inner and outer aqueous phases, the size of the aqueous drops formed at the first junction decreases. Since the volumetric flow rate of the inner aqueous phase is fixed, the reduction in droplet size leads to an increase in the breakup rate at the first junction, increasing the number of internal drops in each outer drop.

The number of inner drops in a three-phase glass capillary device that combines a coflow and a flow-focusing geometry can be controlled by varying the flow rates of the three phases independently (Lee \& Weitz, 2009). In the dripping regime occurring at low flow rates of all phases, the interfacial tension between the middle and outer phases dominates the droplet breakup process and the generated multiple emulsion droplets have only one internal drop $(\mathrm{N}=1)$ (Fig. 9a). As the inertial force of the middle and inner phases becomes comparable to the interfacial tension, the droplet breakup occurs in the dripping-to-jetting transition regime, i.e. the internal droplets are formed in the dripping regime and the outer drops are formed in the jetting regime, and therefore $\mathrm{N}>1$ (Figs. 12a-b). The number of inner droplets in each outer drop can be tuned by varying the flow rates of the three phases. For example, $\mathrm{N}$ increases gradually with increasing the flow rate of the middle and inner phase and with decreasing the flow rate of the outer phase. Eventually, at relatively high flow rates of the middle and inner phase, the inertial force of these phases overcomes the interfacial tension and both the middle and inner phase forms a jet. The multiple emulsions formed in this pure jetting regime are polydisperse with a wide variation of $\mathrm{N}$ among individual droplets.

Using one-step drop formation process shown in Fig. 12a, it is difficult to control independently the size and number of inner droplets and increasingly more complicated to 
encapsulate more than two inner droplets. Glass capillary devices with sequential co-flow drop generators are more suitable to form multiple emulsions containing a controlled number of drops at each hierarchical level and the size of the drops at each level was adjusted independently (Chu et al., 2007; Li et al., 2014). The device for making double O/W/O or $\mathrm{W} / \mathrm{O} / \mathrm{W}$ emulsions is comprised of the injection tube, a cylindrical capillary with a tapered end, which is inserted into the transition tube, a second cylindrical capillary of inner diameter $\mathrm{D}_{2}$ (Fig. 12b). Both cylindrical capillaries are placed within a square capillary. The other end of the transition tube is again tapered and inserted into a third cylindrical capillary, the collection tube, of inner diameter $D_{3}$. The droplets of the inner fluid are emulsified in the first stage of the device by coaxial flow of the middle fluid. The single emulsion is subsequently emulsified in the second stage through coaxial flow of the outer fluid, which is injected through the square capillary.

\section{High-order multiple emulsions with controlled number of drops at each hierarchical level (Figure 1e)}

Chu et al. (2007) made triple emulsions with controlled number of drops at each hierarchical level using glass capillary device with three sequential co-flow emulsification stages (Fig. 13). The number of innermost droplets $\left(N_{1}\right)$ was controlled between 1 and 7 and the number of middle phase droplets $\left(N_{2}\right)$ was controlled between 1 and 3 using:

$$
\begin{aligned}
& N_{1}=\frac{f_{1}}{f_{2}}=\frac{Q_{1} /\left(\pi d_{1}^{3} / 6\right)}{\left(Q_{1}+Q_{2}\right) /\left(\pi d_{2}^{3} / 6\right)}=\frac{Q_{1}}{Q_{1}+Q_{2}} \frac{d_{2}^{3}}{d_{1}^{3}} \\
& N_{2}=\frac{f_{2}}{f_{3}}=\frac{\left(Q_{1}+Q_{2}\right) /\left(\pi d_{2}^{3} / 6\right)}{\left(Q_{1}+Q_{2}+Q_{3}\right) /\left(\pi d_{3}^{3} / 6\right)}=\frac{Q_{1}+Q_{2}}{Q_{1}+Q_{2}+Q_{3}} \frac{d_{3}^{3}}{d_{2}^{3}}
\end{aligned}
$$


Thus, the number and diameter of the droplets at each level can be predicted from the fluid flow rates, $Q_{i}$ and the diameters of the collection tubes, $D_{i}$ (the subscripts $1,2,3$, and 4 refer to the inner phase, middle phase 1 , middle phase 2 and outer phase, respectively):

$$
\begin{aligned}
& N_{1}=\frac{Q_{1}}{Q_{1}+Q_{2}} \frac{D_{3}^{3}}{D_{2}^{3}}\left[\frac{b_{2}+a_{2}\left(Q_{1}+Q_{2}\right) / Q_{3}}{b_{1}+a_{1}\left(Q_{1} / Q_{2}\right)}\right]^{3} \\
& N_{2}=\frac{Q_{1}+Q_{2}}{Q_{1}+Q_{2}+Q_{3}} \frac{D_{4}^{3}}{D_{3}^{3}}\left[\frac{b_{3}+a_{3}\left(Q_{1}+Q_{2}+Q_{3}\right) / Q_{4}}{b_{2}+a_{2}\left(Q_{1} / Q_{2}\right) / Q_{3}}\right]^{3} \\
& d_{1}=D_{2}\left[b_{1}+a_{1}\left(Q_{1} / Q_{2}\right)\right] \\
& d_{2}=D_{3}\left[b_{2}+a_{2}\left(Q_{1}+Q_{2}\right) / Q_{3}\right] \\
& d_{3}=D_{4}\left[b_{3}+a_{3}\left(Q_{1}+Q_{2}+Q_{3}\right) / Q_{4}\right]
\end{aligned}
$$

where $a_{k}$ and $b_{k}$ are the slopes and intercepts of the $d_{k} / D_{k+1}$ vs. $\left(\sum_{k} Q_{i}\right) / Q_{k+1}$ lines.

\section{Multiple emulsion drops consisted of water drops in the oil core protected by an aqueous shell (Figure 1f)}

Liu et al. (2010) generated triple $\left(\mathrm{W}_{1} / \mathrm{O}_{2}\right) / \mathrm{W}_{3} / \mathrm{O}_{4}$ emulsion drops (Fig. 14) that were used as templates of thermo-responsive hydrogel capsules for smart delivery of nanoparticles. A W/O emulsion with nanoparticles dispersed in the water phase was used as the inner phase. The middle phase was an aqueous solution containing NIPAM (monomer), MBA (crosslinker) and AAPH (initiator). Soybean oil containing PGPR was used as the outer phase. The triple emulsion was collected in an oil containing BDK (photoinitiator). The photoinitiator was activated under UV light and diffused to the interface between the outer oil phase and the aqueous shell, where it initiated the polymerization of NIPAM and MBA into PNIPAM. The result is a capsule consisting of a PNIPAM shell that encapsulates an oil drop containing nanoparticle-laden inner water droplets, all in a continuous oil phase. Upon heating from $25^{\circ}$ 
to $50^{\circ} \mathrm{C}$, the PNIPAM shell shrinks, expelling water to the continuous oil phase. However, because of the incompressibility of the core liquids, the shell breaks providing a burst release (“squirting”) of the encapsulated nanoparticles.

\section{Multiple emulsion drops with distinct inner drops (Figure 1g)}

In some applications, multiple incompatible actives or reactants should be stored separately within the same microcapsule to allow reaction and/or release upon triggering. The fabrication of such multi-compartment capsules requires multiple emulsion templates containing distinct inner droplets. The inner drops can be triggered to coalesce and react with each other or release its content into the outer phase by heating, for example if the middle phase is composed of solid lipids (Sun et al., 2010).

Fig. 15a shows production of W/O/W emulsion drops in which two distinct aqueous drops were encapsulated within the same oil drop by integrating on the same chip one hydrophobic cross junction and one hydrophilic T-junction (Okushima et al., 2004). Drops of distinct colour and similar size were alternately formed at the hydrophobic cross-junction by injecting different aqueous streams from two opposite T inlets (Zheng et al., 2004; Pompano et al., 2011). An array of alternately arranged droplets with uniform inter-droplet spacing was carried with the oil phase to the downstream $\mathrm{T}$ junction, where both distinct droplets were jointly encapsulated within the same oil drop, and the latter being dispersed in the outer phase.

Multiple emulsion drops containing inner droplet of two different liquids can be formed in one emulsification step using glass capillary device shown in Fig. 15b. It consists of a dualbore round injection capillary and a single-bore round collection capillary, both inserted inside a square capillary. The bores in the injection capillary are spaced sufficiently far apart to prevent the emerging drops from coalescing with each other before undergoing 
encapsulation in the middle phase. The number of yellow and blue drops, $\mathrm{N}_{\text {yellow }}$ and $\mathrm{N}_{\text {blue }}$, encapsulated in each outer drop is given by (Adams et al., 2012):

$$
\begin{aligned}
& N_{\text {yellow }}=\frac{f_{\text {yellow }}}{f_{\text {outer }}}=\frac{Q_{\text {yellow }}}{V_{\text {yellow }}} \frac{V_{\text {outer }}}{Q_{\text {blue }}+Q_{\text {yellow }}+Q_{\text {middle }}} \\
& N_{\text {blue }}=\frac{f_{\text {blue }}}{f_{\text {outer }}}=\frac{Q_{\text {blue }}}{V_{\text {blue }}} \frac{V_{\text {outer }}}{Q_{\text {blue }}+Q_{\text {yellow }}+Q_{\text {middle }}}
\end{aligned}
$$

From Eqs. (9) and (10) it follows that $N_{\text {yellow }} / N_{\text {blue }}=Q_{\text {yellow }} / V_{\text {yellow }} \times V_{\text {blue }} / Q_{\text {blue }}$. Therefore, multiple emulsions containing inner drops of the same size $\left(V_{\text {yellow }}=V_{\text {blue }}\right)$ with equal number of yellow and blue drops can be produced using identical flow rates of the inner phases $\left(Q_{\text {yellow }}=Q_{\text {blue }}\right)$. At low flow rates of all phases, and therefore in the dripping regime for both inner and middle phase, the number of inner drops is small. When inner fluids are dripping and the middle fluid is jetting, large numbers of inner drops are encapsulated in the outer drop. By employing both dripping and jetting regimes of inner fluids in two bores of the injection capillary, it is possible to encapsulate inner drops of two different sizes into outer drops: e.g., large yellow drops can be combined with much smaller blue drops. These multiple emulsion droplets can serve as templates of multiple polymersomes for programmed release of multiple components (Kim et al., 2011b) or multi-compartment hydrogel particles containing different oil cores for thermo-induced synergetic release (Wang et al., 2014a; 2014b).

Three or four different inner phases can be injected using a triple-bore or quadruplebore injection capillary, respectively (Adams et al., 2012). Each inner phase is delivered through a different bore and forms different drops in the middle phase. The middle phase breaks up after entering the right capillary, resulting in multiple emulsion drops with 3 or 4 distinct drops. Instead of using a single injection capillary with multiple bores, a bundle of multiple single-bore capillaries can be used to inject different phases into the middle phase. In Fig. 15c, four separate injection tubes were used to produce barcode particles consisting of four different photonic crystal cores embedded in a single polyethylene glycol shell (Zhao et 
al., 2012). Multiple emulsion droplets with multiple cores can be also generated using glass capillary devices with sequential drop generation in co-flowing streams (Wang et al., 2011).

\section{Janus and ternary droplets (Figure 1h)}

Nisisako et al. (2006) produced Janus droplets in a quartz glass microfluidic chip consisting of two junctions: upstream Y-junction was used to form a two-phase organic stream, which was disintegrated into Janus drops in a downstream cross junction (Fig. 16a). To produce bicolored polymeric particles for electronic paper, two separate isobornyl acrylate monomer streams (black and white, IF1 and IF2) were introduced into the chip via Yjunction. A combined black-and-white stream was pinched off into Janus drops by introducing an aqueous PVA stream through two downstream side inlets. Bicolored particles were synthesized by suspension polymerization of the generated droplets. A high-throughput synthesis of polymeric Janus particles was achieved using glass chips consisting of 72 or 128 radially arranged drop generation units (Nisisako et al., 2012; Nisisako \& Torii, 2008). Fig. $16 \mathrm{~d}$ shows a $30 \times 30 \mathrm{~mm}$ microchannel plate with 72 drop generation units used to produce polymeric Janus particles with a diameter of $141 \mu \mathrm{m}$ and a CV of $1.4 \%$ at $70 \mathrm{ml} \mathrm{h}^{-1}$.

Ternary droplets which have three distinct segments on the surface can be produced by injecting IF1 phase into central inlet and IF2 phase into two side inlets of the cross-junction (Fig. 16b). Biconcave polymeric microlenses with two concave spherical surfaces on both sides were produced from ternary droplet templates containing a central photocurable acrylate monomer segment and two lateral non-curable oil segments (Nisisako et al., 2014). Core/shell droplets with two different faces on the shell were formed in the device shown in Fig. 16c. The droplets were used as precursors for the synthesis of Janus hydrogel particles and hollow shells (Seiffert et al., 2010). 
Janus droplets were also formed in the glass capillary device shown in Fig. 16b by stopping the flow of the middle phase, which changes the morphology of the compound drops from two separate inner droplets to a single Janus drop (Zhao et al., 2011). When the flow of the middle phase is switched on again, the middle phase forms a shell around an inner Janus droplet (Fig. 1h, see Janus core).

\section{Non-spherical Janus droplets (Figure 1i)}

Discoidal Janus droplets were produced by confining the generated drops using shallow microchannels (Shepherd et al., 2006). If the volume of the generated drop exceeds that of the largest sphere which could be accommodated in the collection channel, the droplet is deformed into a disk (Xu et al., 2005). Since non-spherical droplets are unstable and tend to regain spherical shape, they have to be solidified in-situ to preserve their shape.

\section{Conclusions}

Membrane, microchannel and microfluidic emulsification devices are powerful tools for preparation of controllable multiple emulsions with uniform drop sizes. Membrane emulsification is used to produce multiple emulsions with a moderate drop polydispersity of 10-20\% via a two-step emulsification process involving conventional homogenization to form internal droplets, followed by injection of the primary emulsion through the membrane to enclose internal droplets in the middle phase drops. Silicon microchannel array devices enable formation of highly uniform outer drops with a polydispersity of less than $5 \%$, as a result of spontaneous, interfacial-tension driven, pinch-off of confined droplets.

Microfluidic emulsification devices such as planar and non-planar junctions, flow focusing devices and glass capillary devices can generate double, triple, quadruple, and quintuple multiple emulsion drops with a polydispersity in the dripping regime of less than 
$3 \%$ and the encapsulation efficiency of $100 \%$. Furthermore, they allow precise control over the size, number and type of inner drops at each hierarchical level. Planar microfluidic devices form multiple emulsions through sequential drop generation using the-junctions with alternating wettability, but the drop generation must be synchronized in all junctions. In nonplanar junctions, the continuous phase fully surrounds the dispersed phase and de-wet it from the walls, which means that there is no need to locally modify the surface wettability of the walls. In glass capillary devices, drop generation is inherently synchronised, since inner and outer drops are formed at a single location in the device and almost simultaneously. Core/shell drops are formed by combining co-flow and counter-current flow focusing and a shell thickness can be made as small as $100 \mathrm{~nm}$ by exploiting a biphasic flow in the injection capillary.

Multi-component multiple emulsion drops composed of different types of inner droplets can be formed by injecting two or more different dispersed phases through separate bores of a dual-, triple-, and quadruple-bore injection capillary or injecting different dispersed phases through separate single-bore injection capillaries. Moreover, microfluidic fabrication methods can be used to form non-spherical drops such as discoidal and rod-like drops and the drops composed of two or three distinct regions on the surface with different properties.

The main challenges of drop microfluidics that will have to be tackled in the future are susceptibility of microfluidic channels to fouling and wetting, complex start-up and cleaning procedures, and scale-up problems. Further growth of microfluidic emulsification technology will be directed towards development of new strategies of two-dimensional and threedimensional integration of large number of drop generation units into highly parallelized systems. It should enable increase in the drop productivity from several grams per hour to several kilograms per hour or even more. 


\section{References}

Abate, A. R., \& Weitz, D. A. (2009). High-order multiple emulsions formed in poly(dimethylsiloxane) microfluidics, Small, 5, 2030-2032.

Abate, A. R., Thiele, J., \& Weitz, D. A. (2011). One-step formation of multiple emulsions in microfluidics, Lab Chip, 11, 253-258.

Adams, L. L. A., Kodger, T. E., Kim, S. H., Shum, H. C., Franke, T., \& Weitz, D. A. (2012). Single step emulsification for the generation of multi-component double emulsions, Soft Matter, 8, 10719-10724.

Anna, S. L., Bontoux, N., \& Stone, H. A. (2003). Formation of dispersions using “flow focusing", in microchannels, Appl. Phys. Lett., 82, 364-366.

Aryanti, N., Williams, R. A., Hou, R., \& Vladisavljević, G. T. (2006). Performance of rotating membrane emulsification for O/W production, Desalination, 200, 572-574.

Bauer, W. A. C., Fischlechner, M., Abell, C., \& Huck, W. T. S. (2010). Hydrophilic PDMS microchannels for high-throughput formation of oil-in-water microdroplets and water-in-oilin-water double emulsions, Lab Chip, 10, 1814-1819.

Benson, B. R., Stone, H. A., \& Prud'homme, R. K. (2013). An “off-the-shelf” capillary microfluidic device that enables tuning of the droplet breakup regime at constant flow rates, Lab Chip, 13, 4507-4511.

Berendsen, R., Güell, C., \& Ferrando, M. (2015). Spray dried double emulsions containing procyanidin-rich extracts produced by premix membrane emulsification: Effect of interfacial composition, Food Chem., 178, 251-258.

Chang, F. C., \& Su, Y. C. (2008). Controlled double emulsification utilizing 3D PDMS microchannels, J. Micromech. Microeng., 18, 065018.

Chen, P. W., Cadisch, G., \& Studart, A. R. (2014). Encapsulation of aliphatic amines using microfluidics, Langmuir, 30, 2346-2350. 
Chu, L. Y., Utada, A. S., Shah, R. K., Kim, J. W., \& Weitz, D. A. (2007). Controllable monodisperse multiple emulsion, Angew. Chem., Int. Ed. Engl., 46, 8907-8974.

Datta, S. S., Abbaspourrad, A., Amstad, E., Fan, J., Kim, S. H., Romanowsky, M., Shum, H. C., Sun, B., Utada, A. S., Windbergs, M., Zhou, S., \& Weitz, D. A. (2014). 25th Anniversary article: double emulsion templated solid microcapsules: mechanics and controlled release, Adv. Mater., 26, 2205-2218.

Dragosavac, M. M., Holdich, R. G., Vladisavljević, G. T., \& Sovilj, M. N. (2012). Stirred cell membrane emulsification for multiple emulsions containing unrefined pumpkin seed oil with uniform droplet size, J. Membr. Sci., 392-393, 122-129.

Garstecki, P., Fuerstman, M. J., Stone, H. A., \& Whitesides, G. M. (2006). Formation of droplets and bubbles in a microfluidic T-junction-scaling and mechanism of break-up, Lab Chip, 6, 437-446.

Garti, N. (1997). Double emulsions: scope, limitations and new achievements, Colloids Surf., A, 123-124, 233-246.

Graber, M. (2010). Transport phenomena in rotating membrane processed W/O/W emulsions (PhD Thesis). Zurich: Institute of Food, Nutrition, and Health, Laboratory of Food Process Engineering, ETH Zurich, Switzerland.

Higashi, S., Shimizu, M., Nakashima, T., Iwata, K., Uchiyama, F., Tateno, S., \& Setoguchi T. (1995). Arterial-injection chemotherapy for hepatocellular-carcinoma using monodispersed poppy-seed oil microdroplets containing fine aqueous vesicles of epirubicin - initial medical application of a membrane-emulsification technique, Cancer, 75, 1245-1254.

Higashi, S., Tabata, N., Kondo, K., Maeda, Y., Shimizu, M., Nakashima, T., \& Setoguchi T. (1999). Size of lipid microdroplets effects results of hepatic arterial chemotherapy with an anticancer agent in water-in-oil-in-water emulsion to hepatocellular carcinoma, J. Pharmacol. Exp. Ther., 289, 816-819. 
Higashi S, \& Setoguchi, T. (2000). Hepatic arterial injection chemotherapy for hepatocellular carcinoma with epirubicin aqueous solution as numerous vesicles in iodinated poppy-seed oil microdroplets: clinical application of water-in-oil-in-water emulsion prepared using a membrane emulsification technique, Adv Drug Deliv Rev, 45, 57-64.

Holdich, R. G., Dragosavac, M. M., Vladisavljević, G. T., \& Kosvintsev, S. R. (2010). Membrane emulsification with oscillating and stationary membranes, Ind. Eng. Chem. Res., 49, 3810-3817.

Holdich, R. G., Dragosavac, M. M., Vladisavljević, G. T., \& Piacentini, E. (2013). Continuous membrane emulsification with pulsed (oscillatory) flow, Ind. Eng. Chem. Res., 52, 507-515.

Josephides, D. N., \& Sajjadi, S. (2015). Microfluidic method for creating monodisperse viscous single emulsions via core-shell templating, Microfluid. Nanofluid., 18, 383-390.

Kanai, T., Lee, D., Shum, H. C., \& Weitz, D. A. (2010). Fabrication of tunable spherical colloidal crystals immobilized in soft hydrogels, Small, 6, 807-810.

Kawakatsu, T., Kikuchi, Y., \& Nakajima, M. (1997). Regular-sized cell creation in microchannel emulsification by visual microprocessing method, J. Am. Oil Chem. Soc., 74, $317-321$.

Kawakatsu, T., Trägårdh, G., \& Trägårdh, C. (2001). Production of W/O/W emulsions and S/O/W pectin microcapsules by microchannel emulsification, Colloid Surf. A, 189, 257-264.

Kim, H. J., Decker, E. A., \& McClements, D. J. (2006). Preparation of multiple emulsions based on thermodynamic incompatibility of heat-denatured whey protein and pectin solutions, Food Hydrocolloids, 20, 586-595.

Kim, J. W., Utada, A. S., Fernández-Nieves, A., Hu, Z., \& Weitz, D. A. (2007). Fabrication of monodisperse gel shells and functional microgels in microfluidic devices, Angew. Chem. Int. Ed., 46, 1819-1822. 
Kim, S. H., \& Weitz, D. A. (2011). One-step emulsification of multiple concentric shells with capillary microfluidic devices, Angew. Chem., Int. Ed. Engl., 50, 8731-8734.

Kim, S. H., Kim, J. W., Cho, J. C., \& Weitz, D. A. (2011a). Double-emulsion drops with ultra-thin shells for capsule templates, Lab Chip, 11, 3162-3166.

Kim, S. H., Shum, H. C., Kim, J. W., Cho, J. C., \& Weitz, D. A. (2011b). Multiple polymersomes for programmed release of multiple components. J. Am. Chem. Soc., 133, 15165-15171.

Kobayashi, I., Nakajima, M., Chun, K., Kikuchi, Y., \& Fujita, H. (2002). Silicon array of elongated through-holes for monodisperse emulsion droplets, AIChE J., 48, 1639-1644.

Kobayashi, I., Mukataka, S., \& Nakajima, M. (2004). Effect of slot aspect ratio on droplet formation from silicon straight-through microchannels, J. Colloid Interface Sci., 279, $277-280$.

Kobayashi, I., Lou, X. F, Mukataka, S., \& Nakajima, M. (2005a). Preparation of monodisperse water-in-oil-in-water emulsions using microfluidization and straight-through microchannel emulsification, J. Am. Oil Chem. Soc., 82, 65-71.

Kobayashi, I., Mukataka, S., \& Nakajima, M. (2005b). Production of monodisperse oil-inwater emulsions using a large silicon straight-through microchannel plate, Ind. Eng. Chem. Res., 44, 5852-5856.

Kobayashi, I., Mukataka, S., \& Nakajima, M. (2005c). Novel asymmetric through-hole array microfabricated on a silicon plate for formulating monodisperse emulsions, Langmuir, 21, $7629-7632$.

Kobayashi, I., Wada, Y., Uemura, K., \& Nakajima, M. (2010). Microchannel emulsification for mass production of uniform fine droplets: integration of microchannel arrays on a chip, Microfluid. Nanofluid., 8, 255-262. 
Kobayashi, I., Neves Marcos, A., Wada, Y., Uemura, K., \& Nakajima, M. (2012). Large microchannel emulsification device for mass producing uniformly sized droplets on a liter per hour scale, Green Process. Sci., 1, 353-362.

Kosvintsev, S. R., Gasparini, G., Holdich, R. G., Cumming, I.W., \& Stillwell, M. T. (2005). Liquid-liquid membrane dispersion in a stirred cell with and without controlled shear, Ing. Eng. Chem. Res., 44, 9323-9330.

Kukizaki, M., \& Goto, M. (2007). Preparation and evaluation of uniformly sized solid lipid microcapsules using membrane emulsification, Colloid Surf. A, 293, 87-94.

Kukizaki, M. (2009a). Shirasu porous glass (SPG) membrane emulsification in the absence of shear flow at the membrane surface: Influence of surfactant type and concentration, viscosities of dispersed and continuous phases, and transmembrane pressure, J. Membr. Sci., 327, 234-243.

Kukizaki, M. (2009c). Preparation of solid lipid microcapsules via solid-in-oil-in-water dispersions by premix membrane emulsification, Chem. Eng. J., 151: 387-396.

Lee, D., \& Weitz, D. A. (2008). Double emulsion-templated nanoparticle colloidosomes with selective permeability, Adv. Mater., 20, 3498-3503.

Lee, D., \& Weitz, D. A. (2009). Nonspherical colloidosomes with multiple compartments from double emulsions, Small, 5, 1932-1935.

Li, E. Q., Zhang, J. M., \& Thoroddsen, S. T. (2014). Simple and inexpensive microfluidic devices for the generation of monodisperse multiple emulsions, J. Micromech. Microeng., 24, 015019.

Liu, R., Ma, G. H., Wan, Y. H., \& Su, Z. G. (2005a). Influence of process parameters on the size distribution of PLA microcapsules prepared by combining membrane emulsification technique and double emulsion-solvent evaporation method, Colloid Surf. B, 45, 144-153. 
Liu, R., Ma, G. H., Meng, F. T., \& Su, Z. G. (2005b). Preparation of uniform-sized PLA microcapsules by combining Shirasu Porous Glass membrane emulsification technique and multiple emulsion-solvent evaporation method, J. Controlled Release, 103, 31-43.

Liu, L., Wang, W., Ju, X. J., Xie, R., \& Chu, L. Y. (2010). Smart thermo-triggered squirting capsules for nanoparticle delivery, Soft Matter, 6, 3759-3763.

Lorenceau, E., Utada, A. S., Link, D. R., Cristobal, G., Joanicot, M., \& Weitz, D. A. (2005). Generation of polymerosomes from double emulsions, Langmuir, 21, 9183-9186.

Ma, T., Wang, L., Yang, T., Wang, D., Ma, G., \& Wang, S. (2014). PLGA-lipid liposphere as a promising platform for oral delivery of proteins, Colloids Surf. B, 117, 512-519.

Martino, C., Berger, S., Wootton, R. C. R., \& deMello, A. J. (2014). A 3D-printed microcapillary assembly for facile double emulsion generation, Lab Chip, 14, 4178-4182

Mine, Y., Shimizu, M., \& Nakashima, T. (1996). Preparation and stabilization of simple and multiple emulsions using a microporous glass membrane, Colloid Surf. B, 6, 261-268.

Nakajima, M., Nabetani, H., Ichikawa, S., \& Xu, Q. Y. (2003). Functional emulsions, US Patent 6,538,019.

Nabavi, A. S., Gu, S., Vladisavljević, G. T., \& Ekanem, E. E. (2015a). Dynamics of double emulsion break-up in three phase glass capillary microfluidic devices, J. Colloid Interface Sci., 450, 279-287.

Nabavi, A. S., Vladisavljević, G. T., Gu, S., \& Ekanem, E. E. (2015b). Double emulsion production in glass capillary microfluidic device: Parametric investigation of droplet generation behavior, Chem. Eng. Sci., 130, 183-196.

Nakashima, T., Shimizu, M., \& Kukizaki, M. (1991). Membrane emulsification by microporous glass, Key Eng. Mater., 61-62, 513-516.

Nazir, A., Schroën, K., \& Boom, R. (2013). The effect of pore geometry on premix membrane emulsification using nickel sieves having uniform pores, Chem. Eng. Sci., 93, 173-180. 
Nie, Z., Xu, S., Seo, M., Lewis, P. C., \& Kumacheva, E. (2005). Polymer particles with various shapes and morphologies produced in continuous microfluidic reactors, J. Am. Chem. Soc., $127,8058-8063$.

Nie, Z., Li, W., Seo, M., Xu, S., \& Kumacheva, E. (2006). Janus and ternary particles generated by microfluidic synthesis: Design, synthesis, and self-assembly, J. Am. Chem. Soc., 128, 9408-9412.

Nisisako, T., Okushima, S., \& Torii, T. (2005). Controlled formulation of monodisperse double emulsions in a multiple-phase microfluidic system, Soft Matter, 1, 23-27.

Nisisako, T., Torii, T., Takahashi, T., \& Takizawa, Y. (2006). Synthesis of monodisperse bicolored Janus particles with electrical anisotropy using a microfluidic co-flow system, $A d v$. Mater., 18, 1152-1156.

Nisisako, T., \& Torii, T. (2008). Microfluidic large-scale integration on a chip for mass production of monodisperse droplets and particles, Lab Chip, 8, 287-293.

Nisisako, T., Ando, T., \& Hatsuzawa, T. (2012). High-volume production of single and compound emulsions in a microfluidic parallelization arrangement coupled with coaxial annular world-to-chip interfaces, Lab Chip, 12, 3426-3435.

Nisisako, T., Ando, T., \& Hatsuzawa, T. (2014). Capillary-assisted fabrication of biconcave polymeric microlenses from microfluidic ternary emulsion droplets, Small, 10, 5116-5125.

Okushima, S., Nisisako, T., Torii, T., \& Higuchi T. (2004). Controlled production of monodisperse double emulsions by two-step droplet breakup in microfluidic devices, Langmuir, 20, 9905-9908.

Pautot, S., Frisken, B. J., \& Weitz, D. A. (2003). Engineering asymmetric vesicles, PNAS, 100, 10718-10721. 
Pawlik, A. K., Fryer, P. J., \& Norton, I. T. (2013). Formulation engineering of food emulsions. In J. E. Norton, P. J. Fryer, \& I. T. Norton (Eds.), Formulation engineering of foods (pp. 82-106). Chichester: John Wiley and Sons.

Pawlik, A. K., \& Norton, I. T. (2012). Encapsulation stability of duplex emulsions prepared with SPG cross-flow membrane, SPG rotating membrane and rotor-stator techniques-A comparison, J. Membr. Sci., 415-416, 459-468.

Peyratout, C. S., \& Dähne, L. (2004). Tailor-made polyelectrolyte microcapsules: From multilayers to smart containers, Angew. Chem. Int. Ed., 43, 3762-3783.

Piacentini, E., Giorno, L., Dragosavac, M. M., Vladisavljević, G. T., \& Holdich, R. G. (2013). Microencapsulation of oil droplets using cold water fish gelatine/gum arabic complex coacervation by membrane emulsification, Food Res. Int., 53, 362-372.

Piacentini, E., Drioli, E., \& Giorno, L. (2014). Membrane emulsification technology: Twentyfive years of inventions and research through patent survey, J.Membr. Sci., 468, 410-422.

Pompano, R. R., Liu, W., Du, W., \& Ismagilov, R.F. (2011). Microfluidics using spatially defined arrays of droplets in one, two, and three dimensions, Annu. Rev. Anal. Chem., 4, 59-81.

Romanowsky, M. B., Abate, A. R., Rotem, A., Holtze, C., \& Weitz, D. A. (2012). High throughput production of single core double emulsions in a parallelized microfluidic device, Lab Chip, 12, 802-807.

Rotem, A., Abate, A. R., Utada, A. S., Van Steijn, V., \& Weitz, D. A. (2012). Drop formation in non-planar microfluidic devices, Lab Chip, 12, 4263-4268.

Saeki, D., Sugiura, S., Kanamori, T., Sato, S., \& Ichikawa, S. (2010a). Formation of monodisperse calcium alginate microbeads by rupture of water-in-oil-in-water droplets with an ultra-thin oil phase layer, Lab Chip, 10, 2292-2295. 
Saeki, D., Sugiura, S., Kanamori, T., Sato, S., \& Ichikawa, S. (2010b). Microfluidic preparation of water-in-oil-in-water emulsions with an ultra-thin oil phase layer, Lab Chip, 10, 357-362.

Schroën, K. C. G. P. H., van Rijn, C. J. M., \& Boom, R. M. (2012). Membrane emulsification: Current state of affairs and future challenges, In K. Mohanty, M. K. Purkait (Eds.), Membrane Technologies and Applications (pp. 185-199). Boca Raton: CRC Press.

Shepherd, R. F., Conrad, J. C., Rhodes, S. K., Link, D. R., Marquez, M., Weitz, D. A., \& Lewis, J. A. (2006). Microfluidic assembly of homogeneous and Janus colloid-filled hydrogel granules, Langmuir, 22, 8618-8622.

Shima, M., Kobayashi, Y., Fujii, T., Tanaka, M., Kimura, Y., Adachi, S., \& Matsuno. R. (2004). Preparation of fine $\mathrm{W} / \mathrm{O} / \mathrm{W}$ emulsion through membrane filtration of coarse $\mathrm{W} / \mathrm{O} / \mathrm{W}$ emulsion and disappearance of the inclusion of outer phase solution, Food Hydrocolloids, 18, $61-70$.

Shimoda, M., Miyamae, H., Nishiyama, K., Yuasa, T., Noma, S., \& Igura, N. (2011). Swirlflow membrane emulsification for high throughput of dispersed phase flux through Shirasu porous glass (SPG) membrane, J. Chem. Eng. Jpn, 44, 1-6.

Shum, H. C., Lee, D., Yoon, I., Kodger, T., Weitz, D. A. (2008). Double emulsion templated monodisperse phospholipid vesicles, Langmuir, 24, 7651-7653.

Shum, H. C., Zhao, Y. J., Kim, S. H., \& Weitz, D. A. (2011). Multicompartment polymersomes from double emulsions, Angew. Chem., Int. Ed. Engl., 50, 1648 -1651.

Silva, P. S., Stillwell, M., Williams, B., Dragosavac, M., Vladisavljević, G. T., Bandulasena, H., \& Holdich, R. G. (2015). Azimuthally oscillating membrane emulsification for controlled droplet production, AIChE J., doi: 10.1002/aic.14894. 
Spyropoulos, F., Lloyd, D. M., Hancocks, R. D., \& Pawlik, A. K. (2014). Advances in membrane emulsification. Part A: recent developments in processing aspects and microstructural design approaches, J. Sci. Food Agric., 94, 613-627.

Sugiura, S., Nakajima, M., \& Seki, M. (2002). Prediction of droplet diameter for microchannel emulsification, Langmuir, 18, 3854-3859.

Sugiura, S., Nakajima, M., Yamamoto, K., Iwamoto, S., Oda, T., Satake, M., \& Seki, M. (2004). Preparation characteristics of water-in-oil-in-water multiple emulsions using microchannel emulsification, J. Colloid Interface Sci., 270, 221-228.

Sun, B. J., Shum, H. C., Holtze, C., \& Weitz, D. A. (2010). Microfluidic melt emulsification for encapsulation and release of actives, ACS Appl. Mater. Interfaces, 2, 3411-3416.

Surh, J., Vladisavljević, G. T., Mun, S., \& McClements, D. J. (2007). Preparation and characterization of water/oil and water/oil/water emulsions containing biopolymer-gelled water droplets, J. Agric. Food Chem., 55, 175-184.

Takeuchi, S., Garstecki, P., Weibel, D. B., \& Whitesides, G. M. (2005). An axisymmetric flow-focusing microfluidic device, Adv. Mater., 17, 1067-1072.

Thorsen, T., Roberts, R. W., Arnold, F. H., \& Quake, S. R. (2001). Dynamic pattern formation in a vesicle-generating microfluidic device, Phys. Rev. Lett., 86, 4163-4166.

Toorisaka, E., Ono, H., Arimori, K., Kamiya, N., \& Goto, M. (2003). Hypoglycemic effect of surfactant-coated insulin solubilized in a novel solid-in-oil-in-water (S/O/W) emulsion, Int. J. Pharm., 252, 271-274.

Utada, A. S., Lorenceau, E., Link, D. R., Kaplan, P. D., Stone, H. A., \& Weitz, D. A. (2005). Monodisperse double emulsions generated from a microcapillary device, Science, 308, $537-541$. 
Utada, A. S., Chu, L. Y., Fernandez-Nieves, A., Link, D. R., Holtze, C., \& Weitz, D. A. (2007). Dripping, jetting, drops, and wetting: the magic of microfluidics, MRS Bull., 32, $702-708$.

Van der Graaf, S., Schroën, C. G. P. H., \& Boom, R. M. (2005). Preparation of double emulsions by membrane emulsification: a review, J. Membr. Sci., 251, 7-15.

van Dijke, K., Kobayashi, I., Schroën, K., Uemura, K., Nakajima, M., \& Boom, R. (2010). Effect of viscosities of dispersed and continuous phases in microchannel oil-in-water emulsification, Microfluid. Nanofluid., 9, 77-85.

Vericella, J. J., Baker, S. E., Stolaroff, J. K., Duoss, E. B., Hardin, J. O., Lewicki, J., Glogowski, E., Floyd, W. C., Valdez, C. A., Smith, W. L., Satcher, J. H., Bourcier, W. L., Spadaccini, C. M., Lewis, J. A., \& Aines, R. D. (2015). Encapsulated liquid sorbents for carbon dioxide capture, Nat. Commun., 6, 6124.

Vladisavljević, G. T., Tesch, S., \& Schubert, H. (2002). Preparation of water-in-oil emulsions using microporous polypropylene hollow fibers: Influence of some operating parameters on droplet size distribution, Chem. Eng. Process., 41, 231-238.

Vladisavljević, G. T., \& Schubert, H. (2003). Influence of process parameters on droplet size distribution in SPG membrane emulsification and stability of prepared emulsion droplets, $J$. Membr. Sci., 225, 15-23.

Vladisavljević, G. T., Shimizu, M., \& Nakashima, T. (2004). Preparation of monodisperse multiple emulsions at high production rates by multi-stage premix membrane emulsification. J. Membr. Sci., 244, 97-106.

Vladisavljević, G. T., \& Williams, R. A. (2005a). Recent developments in manufacturing emulsions and particulate products using membranes, Adv. Colloid Interface Sci., 113, 1-20. 
Vladisavljević, G. T., Shimizu, M., \& Nakashima, T. (2005b). Permeability of hydrophilic and hydrophobic Shirasu-porous-glass (SPG) membranes to pure liquids and its microstructure, J. Membr. Sci., 250, 69-77.

Vladisavljević, G. T., \& Williams, R. A. (2006a). Manufacture of large uniform droplets using rotating membrane emulsification, J. Colloid Interface Sci., 299, 396-402.

Vladisavljević, G. T., Shimizu, M., \& Nakashima, T. (2006b). Production of multiple emulsions for drug delivery systems by repeated SPG membrane homogenization: Influence of mean pore size, interfacial tension and continuous phase viscosity, J. Membr. Sci., 284, 373-383.

Vladisavljević, G. T., Surh, J., \& McClements, D. J. (2006c). Effect of emulsifier type on droplet disruption in repeated Shirasu porous glass membrane homogenization, Langmuir, 22, 4526-4533.

Vladisavljević, G. T., Kobayashi, I., \& Nakajima, M. (2011). Effect of dispersed phase viscosity on maximum droplet generation frequency in microchannel emulsification using asymmetric straight-through channels, Microfluid. Nanofluid., 10, 1199-1209.

Vladisavljević, G. T., Shum, H. C., \& Weitz, D. A. (2012a). Control over the shell thickness of core/shell drops in three-phase glass capillary devices, Prog. Colloid Polym. Sci., 139, $115-118$.

Vladisavljević, G. T., Kobayashi, I., \& Nakajima, M. (2012b). Production of uniform droplets using membrane, microchannel and microfluidic emulsification devices, Microfluid. Nanofluid., 13, 151-178.

Vladisavljević, G. T., Khalid, N., Neves, M. A., Kuroiwa, T., Nakajima, M., Uemura, K., Ichikawa, S., \& Kobayashi, I. (2013). Industrial lab-on-a-chip: Design, applications and scaleup for drug discovery and delivery, Adv. Drug Delivery Rev., 65, 1626-1663. 
Vladisavljević, G. T., Wang, B., Dragosavac, M. M., \& Holdich, R. G. (2014a). Production of food-grade multiple emulsions with high encapsulation yield using oscillating membrane emulsification, Colloid Surf. A, 458, 78-84.

Vladisavljević, G. T., Shahmohamadi, H., Das, D. B., Ekanem, E. E., Tauanov, Z., \& Sharma, L. (2014b). Glass capillary microfluidics for production of monodispersed poly (dl-lactic acid) and polycaprolactone microparticles: Experiments and numerical simulations, J. Colloid Interface Sci., 418, 163-170.

Vladisavljević, G. T. (2015). Structured microparticles with tailored properties produced by membrane emulsification, Adv. Colloid Interface Sci., doi:10.1016/j.cis.2015.07.013.

Wang, W., Xie, R., Ju, X. J., Luo, T., Liu, L., Weitz, D. A., \& Chu, L. Y. (2011). Controllable microfluidic production of multicomponent multiple emulsions, Lab Chip, 11, 1587-1592.

Wang, W., Zhang, M. J., Xie, R., Ju, X. J., Yang, C., Mou, C. L., Weitz, D. A., \& Chu. L. Y. (2013). Hole-Shell microparticles from controllably evolved double emulsions, Angew. Chem. Int. Ed., 52, $8084-8087$.

Wang, W., Zhang, M. J., \& Chu, L. Y. (2014a). Microfluidic approach for encapsulation via double emulsions, Curr. Opin. Pharmacol., 18, 35-41.

Wang, W., Zhang, M. J., \& Chu, L. Y. (2014b). Functional polymeric microparticles engineered from controllable microfluidic emulsions, Acc. Chem. Res., 47, 373-384.

Xu, S., Nie, Z., Seo, M., Lewis, P., Kumacheva, E., Stone, H. A., Garstecki, P., Weibel, D. B., Gitlin, I., \& Whitesides, G. M. (2005). Generation of monodisperse particles by using microfluidics: control over size, shape, and composition, Angew. Chem., Int. Ed. Engl., 117, 734-738.

Yafei, W., Tao, Z., \& Gang, H. (2006). Structural evolution of polymer-stabilized double emulsions, Langmuir, 67, 67-73.

Yang, J., Hao, D. X., Bi, C. X., Su, Z. G., Wang, L. Y., \& Ma, G. H. (2010). Rapid synthesis 
of uniform magnetic microspheres by combing premix membrane emulsification and in situ formation techniques, Ind. Eng. Chem. Res., 49, 6047-6053.

Yang, S., Guo, F., Kiraly, B., Mao, X., Lu, M., Leong, K. W., \& Huang, T. J. (2012). Microfluidic synthesis of multifunctional Janus particles for biomedical applications, Lab Chip, 12, 2097-2102.

Ye, C., Chen, A., Colombo, P., \& Martinez, C. (2010). Ceramic microparticles and capsules via microfluidic processing of a preceramic polymer, J. R. Soc. Interface, 7, S461-S473.

Yuan, Q., Aryanti, N., Hou, R., \& Williams, R. A. (2009). Performance of slotted pores in particle manufacture using rotating membrane emulsification, Particuology, 7, 114-120.

Zhao, Y., Xie, Z., Gu, H., Jin, L., Zhao, X., Wang, B., \& Gu, Z. (2010). Multifunctional photonic crystal barcodes from microfluidics, NPG Asia Mater., 4, e25.

Zhao, Y., Shum, H. C., Chen, H., Adams, L. L. A., Gu, Z., \& Weitz, D. A. (2011). Microfluidic generation of multifunctional quantum dot barcode particles, J. Am. Chem. Soc., 133, 8790-8793.

Zheng, B., Tice, J. D., \& Ismagilov, R. F. (2004). Formation of droplets of alternating composition in microfluidic channels and applications to indexing of concentrations in droplet-based assays, Anal. Chem., 76, 4977-4982. 


\section{Abbreviations of Chemicals}

AAPH: 2,2'-Azobis(2-amidinopropane) dihydrochloride

Arlacel 83: Sorbitan sesquioleate

Arlacel P135: Dipolyhydroxystearate (PEG-30)

BDK: 2,2-dimethoxy-2-phenylacetophenone

C8TG: Octanoic acid triacylglycerol

$\mathrm{CaNa}_{2}$-EDTA: Calcium disodium ethylendiaminetetraacetate

Chi: Chitosan

CHL: Chloroform

CMC: Carboxymethyl cellulose sodium salt

DCM: Dichloromethane

DGCS: Decaglycerol condensed stearic acid ester

DGML: Decaglycerol monolaurate

EGDMA: ethyleneglycol dimethacrylate

GA: Gum arabic

HBSS: Hank’s balanced salt solution

HCPK: 1-Hydroxycyclohexyl phenyl ketone

IPSO: Iodinated poppy seed oil

LPC: Lysophosphatidylcholine

MBA: N,N’-methylenebisacrylamide

MCT: Medium chain triglycerides

MSW-7S: Decaglycerol monostearate

Myrj 52: Polyyoxyethylene 40 stearate

NIPAM: N-isopropylacrylamide 
PAA: Poly(acrylic acid)

PBA: Poly(normal-butyl acrylate)

PC: Phosphatidylcholine (lecithin)

PGPR: Polyglycerol polyricinoleate (E 476)

PLA: Poly(D,L-lactide)

PNIPAM: Poly(N-isopropylacrylamide)

POPC: 1-Palmitoyl-2-oleoyl-sn-glycero-3-phosphocholine

POPS: 1-Palmitoyl-2-oleoyl-sn-glycero-3-phospho-L-serine

P(St-co-HEMA): Poly(styrene-co-2-hydroxyethyl methacrylate)

PVA: Poly(vinyl alcohol)

PVP: Poly(vinyl pyrrolidone)

PTSA: 1,3,6,8-Pyrenetetrasulfonic acid tetrasodium salt

SDS: Sodium dodecyl sulfate

rhI: Recombinant human insulin

Span 80: Sorbitan monooleate

Span 85: Sorbitan trioleate

THF: Tetrahydrofuran

TPGDA: Tripropyleneglycol diacrylate

TR-DHPE: Texas red labeled 1,2-dihexanoyl-sn-glycero-3-phosphoethanolamine

Tween 20: Polyoxyethylene (20) sorbitan monolaurate

Tween 80: Polyoxyethylene (20) sorbitan monooleate

TGPR: Tetraglycerol polyricinoleate

$\mathrm{VB}_{12}$ : Vitamin $\mathrm{B}_{12}$ (cyanocobalamin)

Vitaflavan Pur'expert: Dry polyphenol extract from the seeds of white grapes

WPI: Whey protein isolate 
Table 1. Formulations used for production of $\mathrm{W}_{1} / \mathrm{O} / \mathrm{W}_{2}$ emulsions using ME.

\begin{tabular}{|c|c|c|c|c|c|}
\hline $\begin{array}{l}\text { Membrane and } \\
\text { method }\end{array}$ & $\begin{array}{l}\text { Mean } \\
\text { pore } \\
\text { size } \\
\end{array}$ & $\begin{array}{c}\text { Mean size } \\
\text { of } \mathrm{W}_{1} / \mathrm{O} \\
\text { drops } \\
\end{array}$ & $\phi$ & Formulation of $\mathrm{W}_{1} / \mathrm{O} / \mathrm{W}_{2}$ emulsion & Author \\
\hline $\begin{array}{c}\text { SPG } \\
\text { (cross-flow DME) }\end{array}$ & $1.0 \mu \mathrm{m}$ & $4.8 \mu \mathrm{m}$ & $\begin{array}{c}\phi_{\mathrm{i}}=30 \\
\text { vol\% }\end{array}$ & $\begin{array}{l}\underline{\mathrm{W}}_{1}: \text { water }+5 \% \text { glucose } \\
\underline{\mathrm{O}}: \text { Soybean oil }+0.5 \% \mathrm{PC}+0.5 \% \\
\mathrm{PGPR} \\
\underline{\mathrm{W}}_{2}: \text { water }+5 \% \text { glucose }+1 \% \mathrm{LPC}\end{array}$ & $\begin{array}{l}\text { (Mine et al., } \\
\text { 1996) }\end{array}$ \\
\hline $\begin{array}{l}\text { Cellulose acetate } \\
\text { (PME) }\end{array}$ & $\begin{array}{l}0.2 \sim 3.0 \\
\mu \mathrm{m}\end{array}$ & $0.7-3.0 \mu \mathrm{m}$ & $\begin{array}{l}\phi_{\mathrm{i}}=30 \\
\text { vol\% } \\
\phi_{\mathbf{0}}=50 \\
\text { vol } \%\end{array}$ & $\begin{array}{l}\underline{\mathrm{W}}_{1}: \text { HBSS }+10^{-4} \mathrm{~mol} / \mathrm{l} \text { PTSA } \\
\underline{\mathrm{O}}: \mathrm{C} 8 \mathrm{TG}+10 \% \text { PGPR } \\
\underline{\underline{\mathrm{W}}_{2}}: \text { HBSS }+2-10 \% \text { DGML }\end{array}$ & $\begin{array}{l}\text { (Shima et al., } \\
\text { 2004) }\end{array}$ \\
\hline $\begin{array}{l}\text { SPG } \\
\text { (DME with } \\
\text { stirring) }\end{array}$ & $\begin{array}{c}10.6 \text { and } \\
20 \mu \mathrm{m}\end{array}$ & $\begin{array}{c}30.1 \text { and } 70 \\
\mu \mathrm{m}, \mathrm{CV}= \\
17 \text { and } 9 \%\end{array}$ & $\begin{array}{c}\phi_{\mathrm{i}}=50 \\
\mathrm{vol} \% \\
\phi_{\mathbf{0}}=67 \\
\mathrm{vol} \%\end{array}$ & $\begin{array}{l}\underline{\mathrm{W}}_{1}: \text { water }+5.8 \% \text { glucose }+1.2 \% \\
\text { epirubicin hydrochloride } \\
\underline{\mathrm{O}}: \text { IPSO }+9 \% \text { PGPR } \\
\underline{\mathrm{W}}_{2}: \text { physiological saline }+1 \% \\
\text { polyoxyethylene } 60 \text { stearate }\end{array}$ & $\begin{array}{c}\text { (Higashi et al., } \\
\text { 1999, 1995, } \\
\text { 2000) }\end{array}$ \\
\hline $\begin{array}{l}\text { SPG (repeated } \\
\text { PME, } n=5-6 \text { ) }\end{array}$ & $10.7 \mu \mathrm{m}$ & $\begin{array}{c}4.4-13.2 \\
\mu \mathrm{m}, \mathrm{span}= \\
0.28-0.4\end{array}$ & $\begin{array}{l}\phi_{\mathrm{i}}=10-30 \\
\quad \text { vol } \% \\
\phi_{\mathbf{0}}=1-60 \\
\quad \text { vol } \%\end{array}$ & $\begin{array}{l}\frac{\mathrm{W}_{1}}{1}: \text { water }+5 \% \text { glucose } \\
\underline{\underline{O}}: \text { soybean oil }+5 \% \text { PGPR } \\
\underline{\underline{W}}_{2}: \text { water }+5 \% \text { glucose }+0.5 \% \text { Tween } \\
80+(1 \% \text { sodium alginate })\end{array}$ & $\begin{array}{l}\text { (Toorisaka et } \\
\text { al., 2003) }\end{array}$ \\
\hline $\begin{array}{c}\text { SPG } \\
\text { (cross-flow DME) }\end{array}$ & $5 \mu \mathrm{m}$ & $\begin{array}{c}17 \mu \mathrm{m}, \\
\text { span = } \\
0.35-0.42\end{array}$ & $\begin{array}{c}\phi_{\mathrm{i}}=10 \\
\quad \text { vol } \% \\
\phi_{\mathbf{0}}=1-10 \\
\quad \text { vol } \%\end{array}$ & 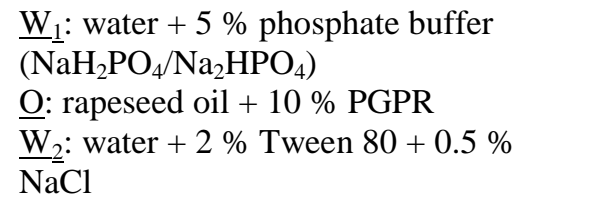 & $\begin{array}{c}\text { (Vladisavljević } \\
\text { \& Schubert, } \\
\text { 2003) }\end{array}$ \\
\hline $\begin{array}{l}\text { Internal pressure- } \\
\text { type SPG micro kit } \\
\text { (DME) }\end{array}$ & $\begin{array}{c}1.0-9.9 \\
\mu \mathrm{m}\end{array}$ & $\begin{array}{l}3.1- \\
32.8 \mu \mathrm{m} \\
\operatorname{span} \approx 0.4\end{array}$ & $\begin{array}{c}\phi_{\mathrm{i}}=40 \\
\mathrm{wt} \% \\
\phi_{\mathrm{o}} \approx 9 \mathrm{wt} \%\end{array}$ & $\begin{array}{l}\underline{\mathrm{W}_{1}}: \text { water }+1 \% \mathrm{VB}_{12} \\
\underline{\mathrm{O}}: \text { tripalmitin }+10 \% \mathrm{TGPR} \text { at } 60{ }^{\circ} \mathrm{C} \\
\underline{\mathrm{W}_{2}}: \text { water }+1 \% \mathrm{DGCS}+0.22 \% \mathrm{NaCl}\end{array}$ & $\begin{array}{l}\text { (Kukizaki \& } \\
\text { Goto, 2007) }\end{array}$ \\
\hline $\begin{array}{c}\text { SPG } \\
\text { (repeated PME, } \\
n=3 \text { ) }\end{array}$ & $10 \mu \mathrm{m}$ & $\begin{array}{c}7.7- \\
10.5 \mu \mathrm{m} \\
\text { span }=0.8- \\
1.0\end{array}$ & $\begin{array}{l}\phi_{\mathrm{i}}=15 \\
\mathrm{wt} \% \\
\phi_{\mathbf{0}}=20 \\
\mathrm{wt} \%\end{array}$ & $\begin{array}{l}\mathrm{W}_{1}: 0.01 \mathrm{M} \text { acetic acid }+10 \% \\
\text { Vitaflavan Pur'expert } \\
\underline{\mathrm{O}} \text { : sunflower oil }+4 \% \text { PGPR } \\
\mathrm{W}_{2}: 0.01 \mathrm{M} \text { acetic acid }+0.5 \% \text { WPI + } \\
(0.25 \% \text { CMC or } 0.5 \% \text { GA or } 0.05 \% \\
\text { Chi })\end{array}$ & $\begin{array}{l}\text { (Berendsen et } \\
\text { al., 2015) }\end{array}$ \\
\hline $\begin{array}{l}\text { Polycarbonate } \\
\text { syringe filter } \\
\text { (repeated PME, } \\
n=5 \text { ) }\end{array}$ & $\begin{array}{c}0.7-2 \\
\mu \mathrm{m}\end{array}$ & $0.7-2.0 \mu \mathrm{m}$ & $\begin{array}{l}\phi_{\mathrm{i}}=10 \\
\mathrm{vol} \% \\
\phi_{\mathbf{0}}=10 \\
\mathrm{vol} \%\end{array}$ & $\begin{array}{l}\underline{\mathrm{W}}_{1}: \text { water }+0.1 \mathrm{M} \mathrm{NaCl}+9 \times 10^{-5} \\
\text { dextran } \\
\underline{\text { O}}: \text { dodecane + Arlacel P135 (PEG-30) } \\
\underline{\underline{W}}_{2}: \text { water + 0.1 M NaCl + SDS (few } \\
\text { cmc) }\end{array}$ & $\begin{array}{l}\text { (Yafei et al., } \\
\text { 2006) }\end{array}$ \\
\hline $\begin{array}{l}\text { External pressure- } \\
\text { type SPG micro kit } \\
\text { (DME) }\end{array}$ & $\begin{array}{c}1.4-10.2 \\
\mu \mathrm{m}\end{array}$ & & $\begin{array}{c}\phi_{\mathrm{i}}=4 \mathrm{vol} \% \\
\phi_{\mathrm{o}} \approx 13 \\
\quad \text { vol } \%\end{array}$ & 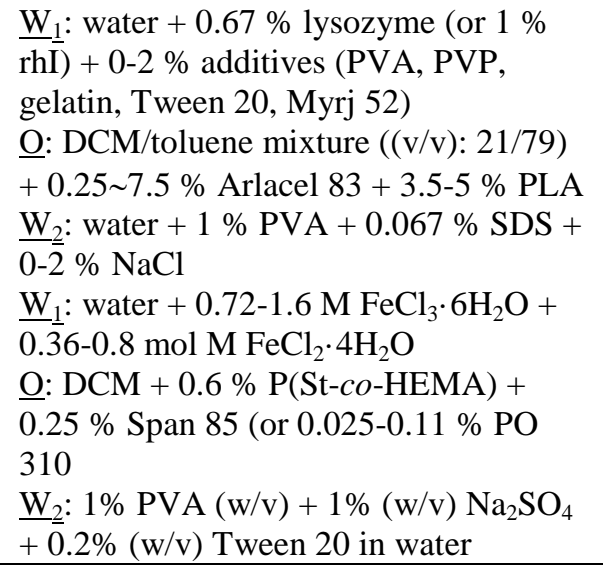 & $\begin{array}{l}\text { (Liu et al., } \\
\text { 2005a,b) }\end{array}$ \\
\hline
\end{tabular}


Table 2. Formulations used for production of core/shell drops in microfluidic devices and particles generated from these drops.

\begin{tabular}{|c|c|c|c|c|c|}
\hline $\begin{array}{l}\text { Microfluidic } \\
\text { device }\end{array}$ & $\begin{array}{c}\text { Channel } \\
\text { width or } \\
\text { orifice size } \\
\end{array}$ & $\begin{array}{c}\text { Mean size } \\
\text { of } \mathrm{W}_{1} / \mathrm{O} \\
\text { drops } \\
\end{array}$ & Formulation of $\mathrm{W}_{1} / \mathrm{O} / \mathrm{W}_{2}$ emulsion & $\begin{array}{c}\text { Particles formed } \\
\text { after shell } \\
\text { solidification } \\
\end{array}$ & Authors \\
\hline $\begin{array}{l}\text { Two serial T- } \\
\text { junctions }\end{array}$ & $\begin{array}{c}60 \text { and } 130 \\
\mu \mathrm{m}\end{array}$ & $\begin{array}{c}83.4 \mu \mathrm{m} \\
\mathrm{CV}=2.8 \%\end{array}$ & $\begin{array}{l}\underline{\mathrm{W}}_{1}: \text { deionized water } \\
\underline{\mathrm{O}}: \text { corn oil }+1 \% \text { CR-310 (TGPR) } \\
\text { or } 0.5 \% \text { lecithin } \\
\underline{\mathrm{W}_{2}}: \text { water }+0.5 \% \text { SDS or } 0.5 \% \\
\mathrm{MSW}-7 \mathrm{~S}\end{array}$ & - & $\begin{array}{l}\text { Okushima et } \\
\text { al. (2004) }\end{array}$ \\
\hline $\begin{array}{l}\text { Glass } \\
\text { capillary } \\
\text { device }\end{array}$ & $\begin{array}{c}50-500 \mu \mathrm{m} \\
\text { orifice }\end{array}$ & $\begin{array}{c}94 \mu \mathrm{m} \\
\mathrm{CV}<3 \%\end{array}$ & $\begin{array}{l}\underline{\mathrm{W}_{1}}: \text { distilled water } \\
\underline{\mathrm{O}}: 0.1-5 \% \text { PBA-PAA }+ \\
\text { toluene/THF mixture containing } \\
50-80 \mathrm{wt} \% \text { toluene } \\
\underline{\mathrm{W}_{2}}: 80 \% \text { glycerol in distilled } \\
\text { water }\end{array}$ & Polymersomes & $\begin{array}{l}\text { Utada et al. } \\
\text { (2005); } \\
\text { Lorenceau } \\
\text { et al. (2005) }\end{array}$ \\
\hline $\begin{array}{l}\text { Glass } \\
\text { capillary } \\
\text { device }\end{array}$ & & $\begin{array}{c}120-200 \\
\mu \mathrm{m}\end{array}$ & $\begin{array}{l}\frac{\mathrm{W}_{1}}{1}: \text { Milli-Q water }+0-5 \text { wt } \% \text { PVA } \\
+0.02 \text { wt } \% 1 \mu \mathrm{m} \text { yellow-green } \\
\text { sulfate-modified microspheres } \\
\underline{\text { O: }} \text { Toluene/CHL mixture }(1.8: 1 \\
\text { v/v) + 0.005-0.01 wt } \% \text { lipids + } \\
0.02 \text { mol\% TR-DHPE } \\
\underline{W}_{2}: \text { Milli-Q water + } 2-10 \text { wt } \% \\
\text { PVA + 0-40 vol\% glycerol }\end{array}$ & $\begin{array}{c}\text { Liposomes } \\
(\mathrm{d}=20-150 \mu \mathrm{m})\end{array}$ & $\begin{array}{l}\text { Shum et al., } \\
\text { (2008) }\end{array}$ \\
\hline $\begin{array}{l}\text { Glass } \\
\text { capillary } \\
\text { device }\end{array}$ & $\begin{array}{l}\text { Injection } \\
10-50 \mu \mathrm{m}, \\
\text { collection } \\
30-500 \mu \mathrm{m}\end{array}$ & $\begin{array}{c}130-170 \\
\mu \mathrm{m}\end{array}$ & $\begin{array}{l}\underline{\mathrm{W}_{1}}: \text { water }+0-2 \mathrm{wt} \% \text { PVA } \\
\underline{\mathrm{O}}: \text { Toluene }+3-22 \mathrm{wt} \% \\
\text { hydrophobic silica nanoparticles } \\
\underline{\mathrm{W}_{2}}: \text { water }+0.2-2 \mathrm{wt} \% \text { PVA }\end{array}$ & Colloidosomes & $\begin{array}{l}\text { Lee \& } \\
\text { Weitz } \\
(2008)\end{array}$ \\
\hline $\begin{array}{l}\text { axisymmetric } \\
\text { PDMS flow } \\
\text { focusing } \\
\text { device }\end{array}$ & $\begin{array}{l}250 \mu \mathrm{m} \\
\text { orifice }\end{array}$ & $\begin{array}{c}50 \sim 300 \\
\mu \mathrm{m}, \\
\mathrm{CV}=2.5 \%\end{array}$ & $\begin{array}{l}\underline{\mathrm{W}}_{1}: \text { water }+0.1 \mathrm{M} 1,6- \\
\text { hexanediamine } \\
\underline{\mathrm{O}}: \text { hexadecane }+2 \%(\mathrm{v} / \mathrm{v}) \text { Span } 80 \\
\underline{\mathrm{W}_{2}}: \text { adipoyl chloride }+ \\
\text { dichloroethane }+ \text { hexadecane } \\
(1: 2: 30 \mathrm{v} / \mathrm{v})\end{array}$ & - & $\begin{array}{c}\text { Takeuchi et } \\
\text { al. (2005) }\end{array}$ \\
\hline $\begin{array}{l}\text { Planar PDMS } \\
\text { flow focusing } \\
\text { device }\end{array}$ & $\begin{array}{c}60 \times 200 \\
\mu \mathrm{m} \text { orifice }\end{array}$ & $\begin{array}{c}20 \sim 150 \\
\mu \mathrm{m}, \\
\mathrm{CV}<2.5 \%\end{array}$ & $\begin{array}{l}\underline{\mathrm{O}}_{1}: \text { silicon oil }+0.2 \sim 2 \text { wt } \% \text { Span } \\
\underline{\mathrm{O}}_{2}: 4 \text { wt.\% HCPK (photoinitiator) } \\
+ \text { TPGDA or EGDMA (monomer) } \\
\underline{\mathrm{W}}_{2}: \text { water }+2 \text { wt } \% \text { SDS }\end{array}$ & $\begin{array}{c}\text { Hollow polymer } \\
\text { particles }\end{array}$ & $\begin{array}{l}\text { Nie et al. } \\
(2005)\end{array}$ \\
\hline
\end{tabular}


(a) Numerous inner drops
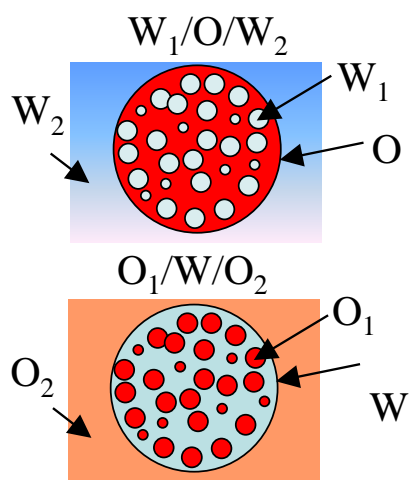

(d) Drops with controlled number of inner drops
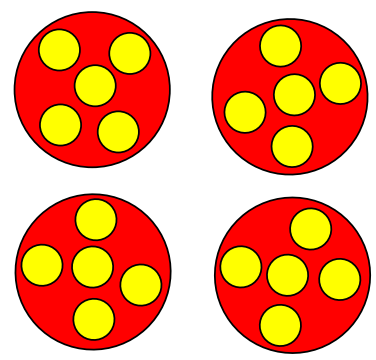

(g) Controlled number of distinct inner drops

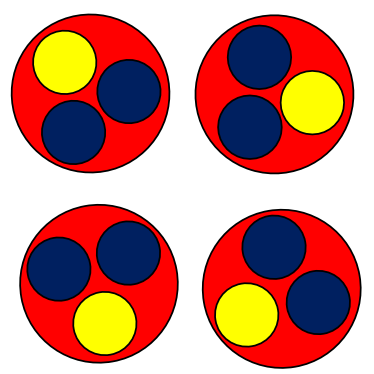

(b) Core-shell drops
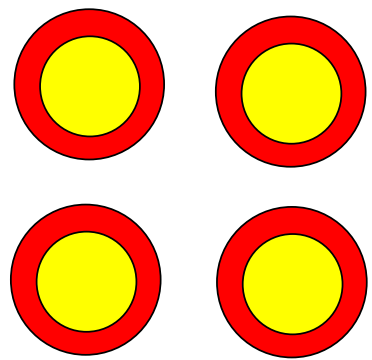

(e) High-order emulsions with controlled number of inner and middle drops

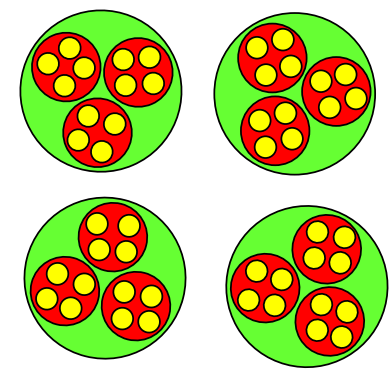

(h) Janus and ternary

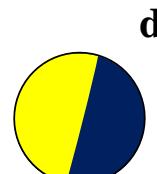

$$
\text { Janus }
$$

drop

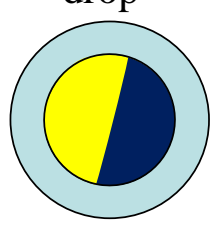

Janus core

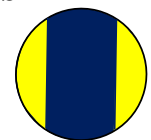

Ternary drop

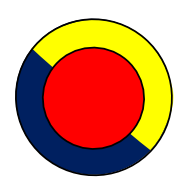

Janus shell
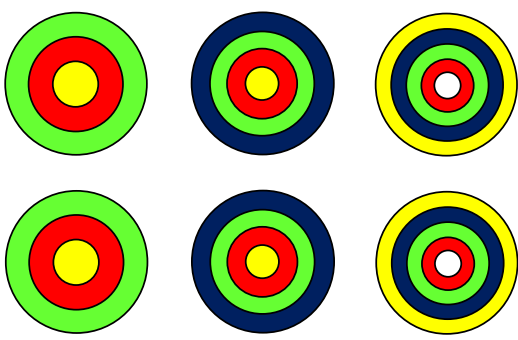

Triple Quadruple Quintuple (f) Core-shell drops with numerous inner drops

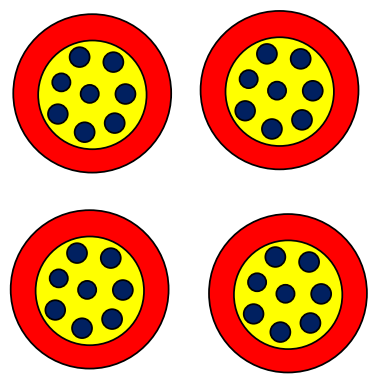

(i) Non-spherical Janus drops
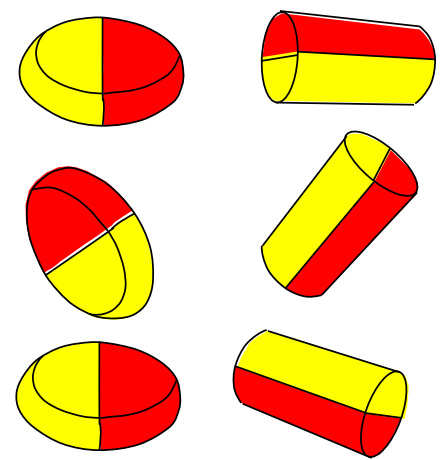

Figure 1. Morphologies of multiple emulsion droplets: (a) Numerous droplets of inner phase; (b) Core-shell droplets (Vladisavljević et al., 2012a); (c) multiple concentric shells (Kim et al., 2011a); (d) Drops with controlled number of inner droplets (2, 3, 4, ...) (Chu et al., 2007); (e) High-order multiple emulsions with controlled number of droplets at each level (Chu et al., 2007); (e) Core/shell droplets with numerous inner droplets (Chu et al., 2007); (g) Distinct inner droplets (Wang et al., 2011); (h) Janus and ternary droplets (Yang et al., 2012; Nie et al., 2006); (i) Non-spherical Janus droplets (Shepherd et al., 2006). 

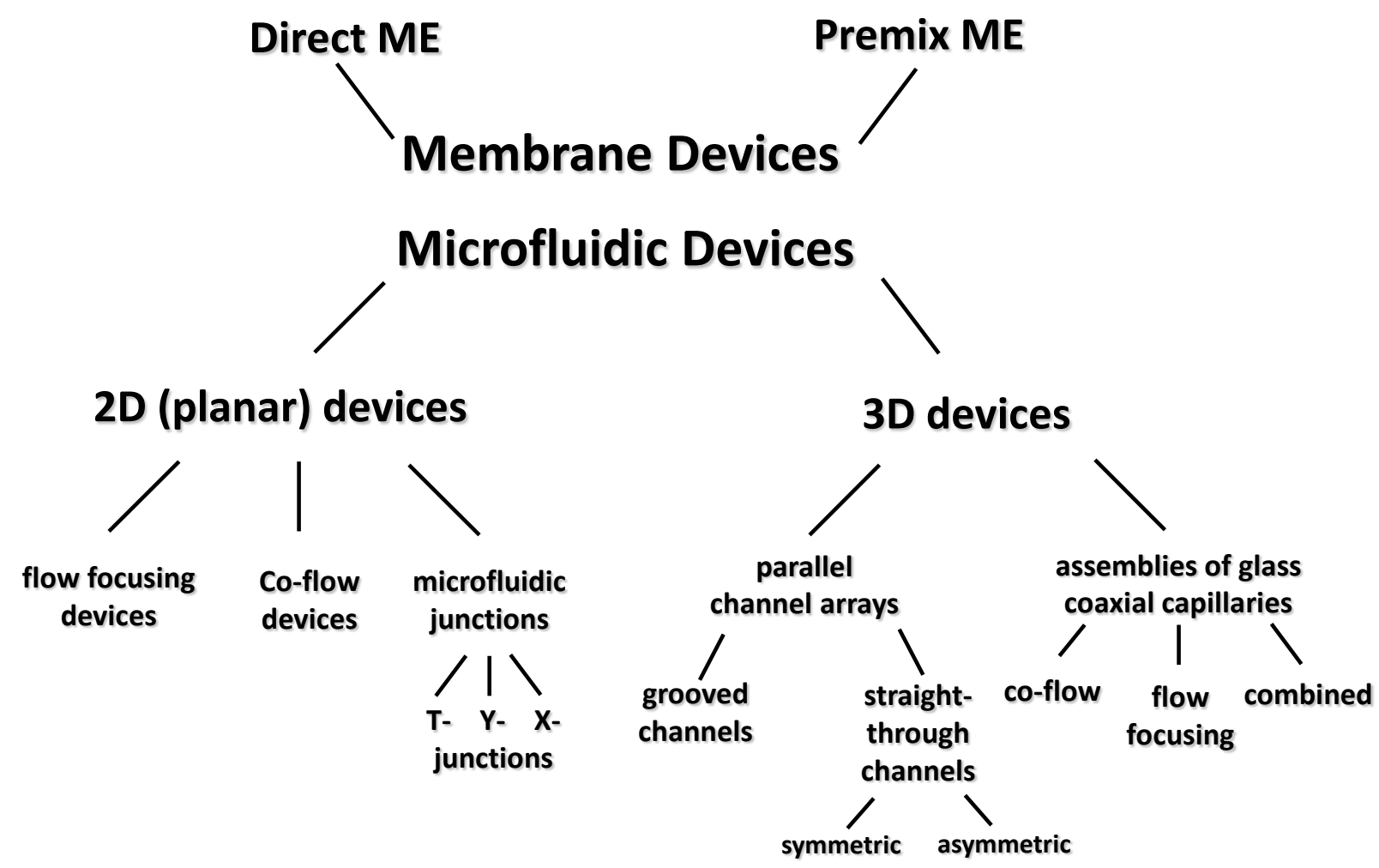

Figure 2. Micro-scale emulsification methods reviewed in this paper. 
(a)

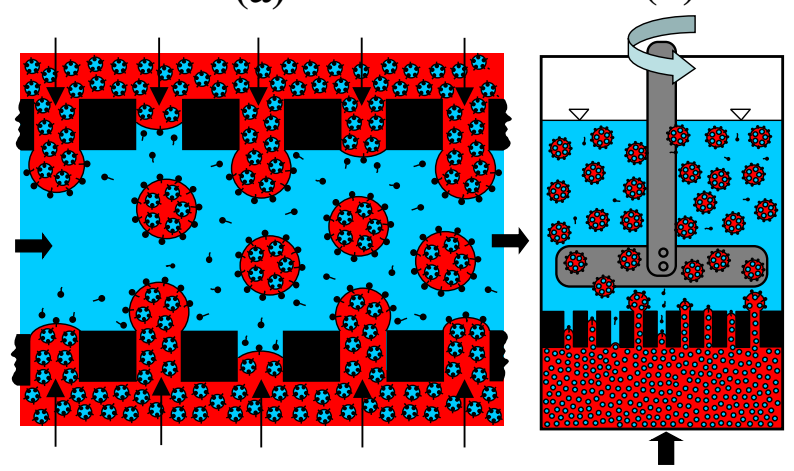

(c)

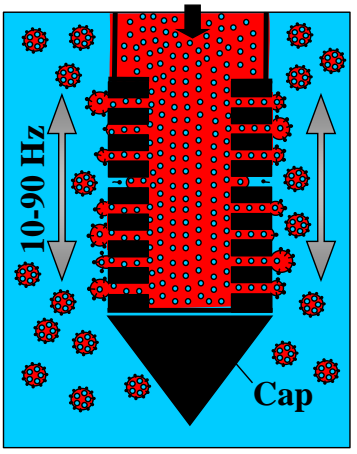

(d)

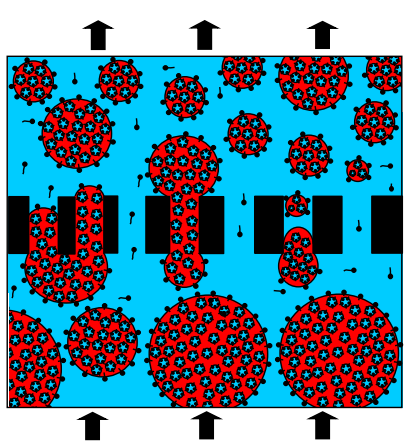

Figure 3. Formation of multiple emulsion using membrane emulsification (ME): (a) Crossflow system (Nakashima et al., 1991); (b) Stirred cell (Kosvintsev et al., 2005); (c) oscillating membrane (Vladisavljević et al., 2014a); (d) Premix ME (Vladisavljević et al., 2004). 
(a)

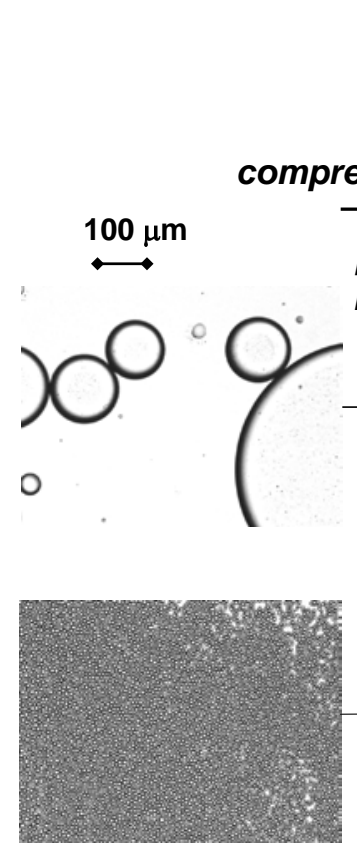

ressure

gauge

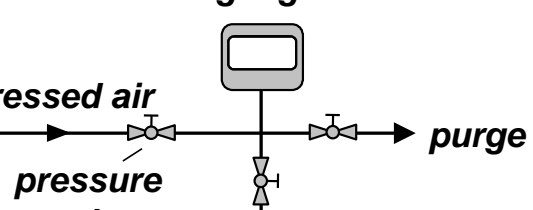

regulator

coarse

emulsion

membrane module

fine emulsion
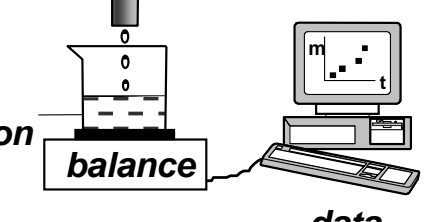

data acquisition (b)
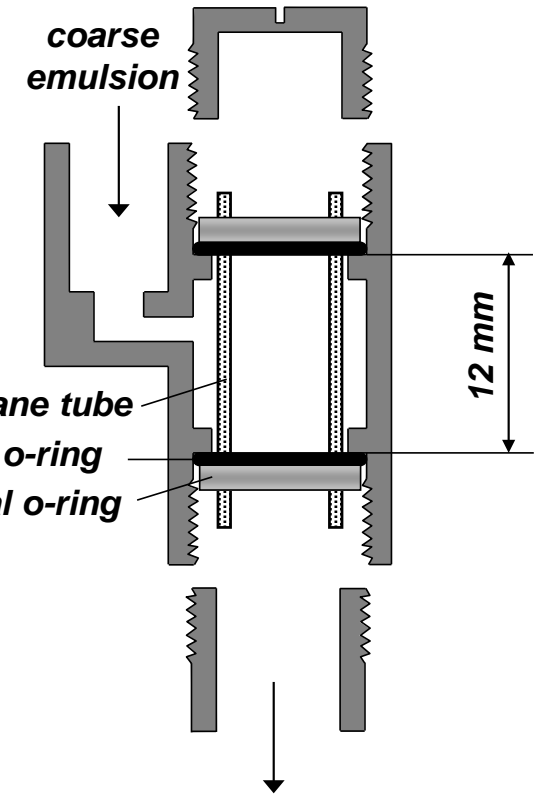

fine emulsion

Figure 4. Preparation of $\mathrm{W}_{1} / \mathrm{O} / \mathrm{W}_{2}$ emulsion using premix ME with SPG membrane: (a) Experimental set-up and micrographs of the premix and product emulsion; (b) A scheme of the membrane module of Kiyomoto Iron Works Company (Vladisavljević et al., 2004; 2006c). 
(a)

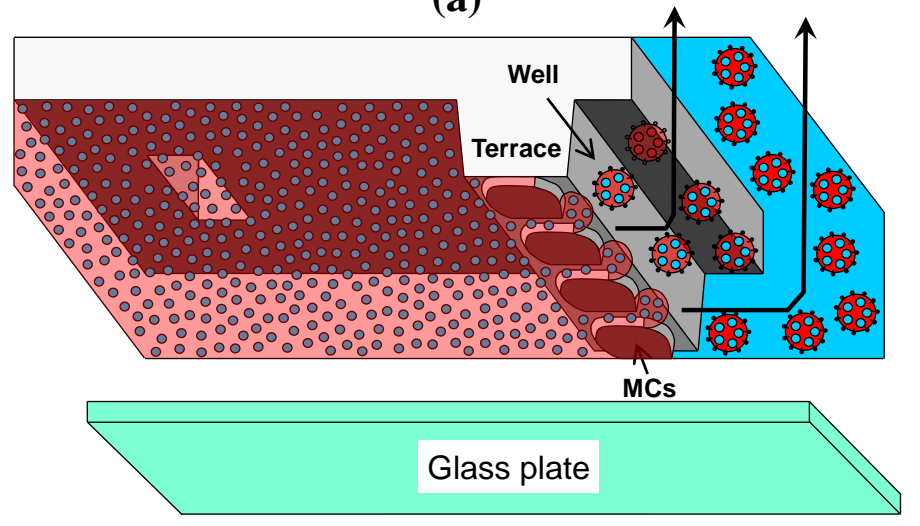

(c)

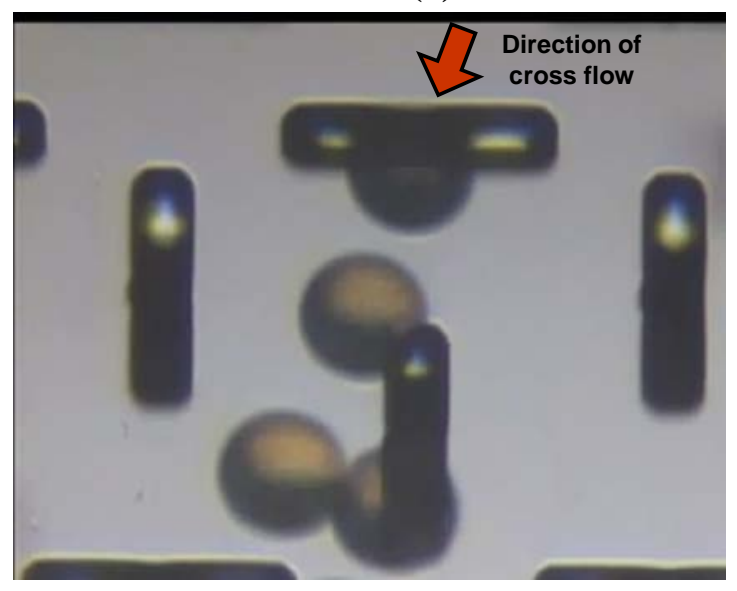

(b)

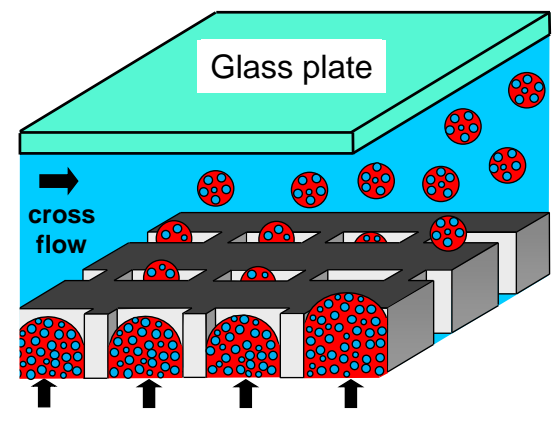

(d)

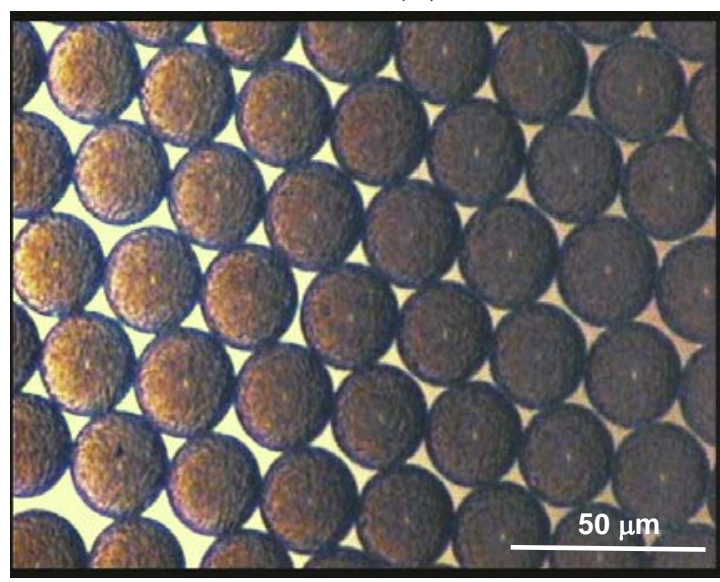

Figure 5. Formation of multiple emulsion using MC emulsification: (a) Grooved-type MC plate (Kawakatsu et al., 2001; Sugiura et al., 2004); Straight-through MC plate (Kobayashi et al., 2005a); (c) Micrograph of $\mathrm{W}_{1} / \mathrm{O} / \mathrm{W}_{2}$ emulsion formation on asymmetric straight-through MC plate containing 20,000 MCs with a size of $50 \times 10 \mu \mathrm{m}$; (d) $\mathrm{W}_{1} / \mathrm{O} / \mathrm{W}_{2}$ emulsion droplets with a diameter of $27 \mu \mathrm{m}$ generated using asymmetric straight-through MC plate shown in (c) (Vladisavljević \& Dragosavac, unpublished). 
Chip 1 with hydrophobic T-junction

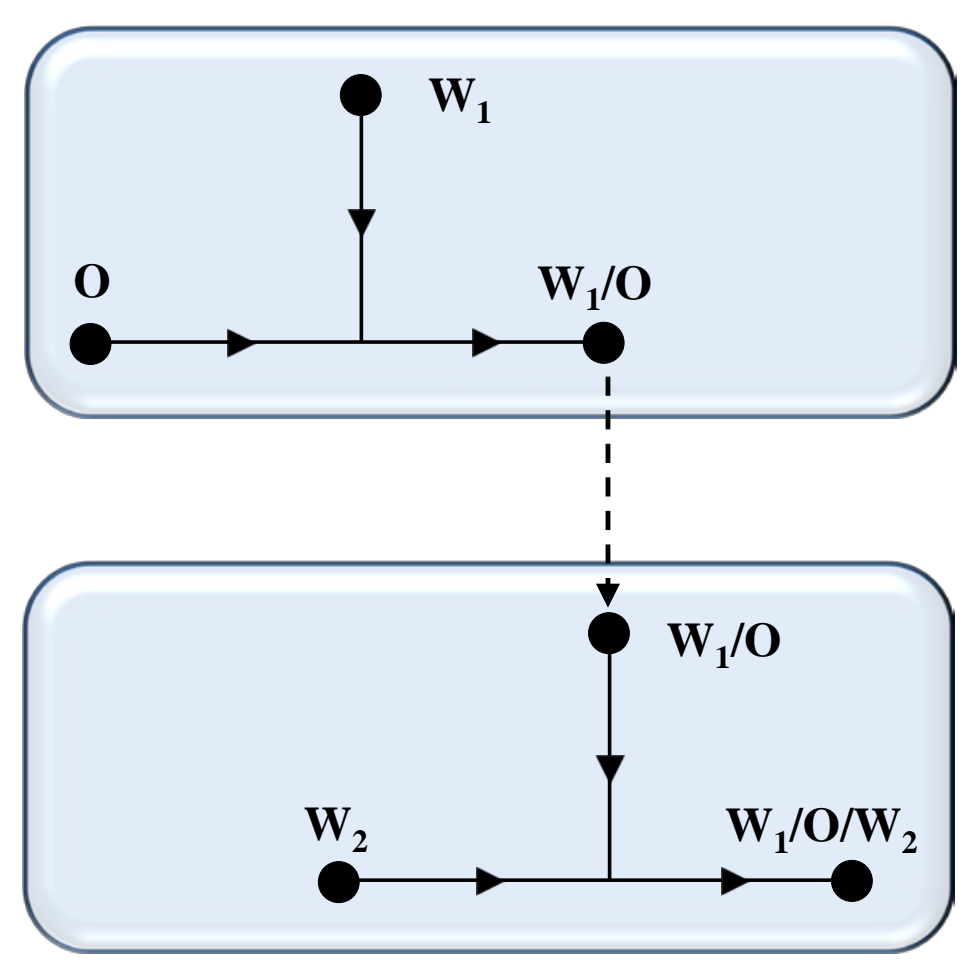

Chip 2 with hydrophilic T-junction

Figure 6. Production of core-shell drops using two separate planar T-junction chips connected in series (Nisisako et al., 2005). 
(a)

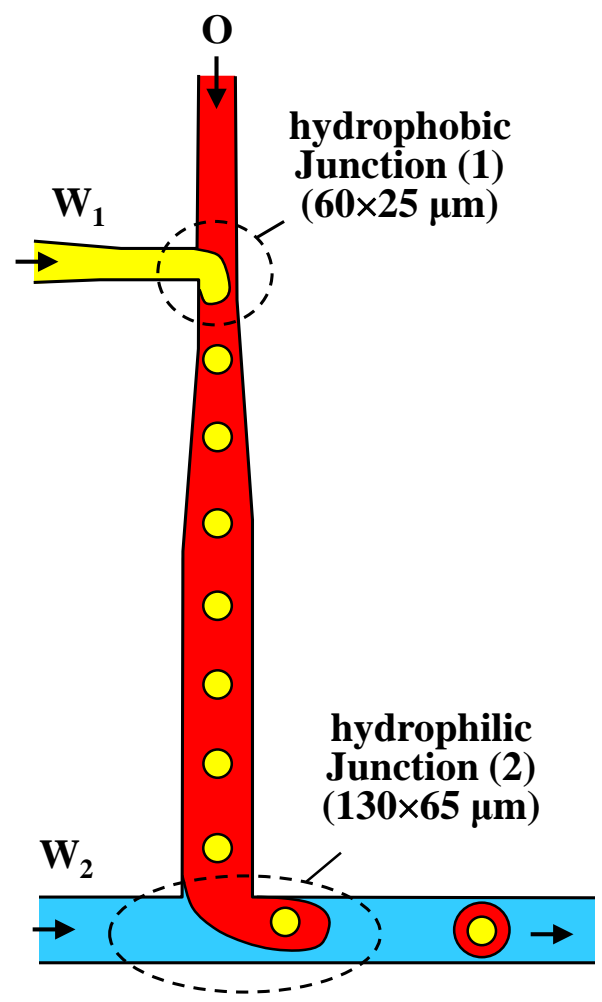

(b)

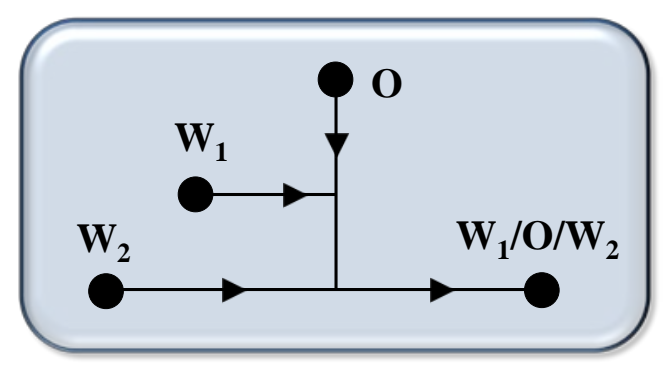

(c)

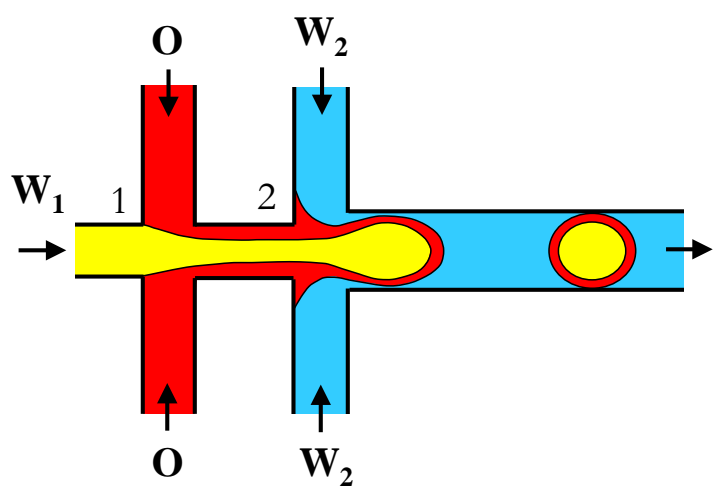

(d)

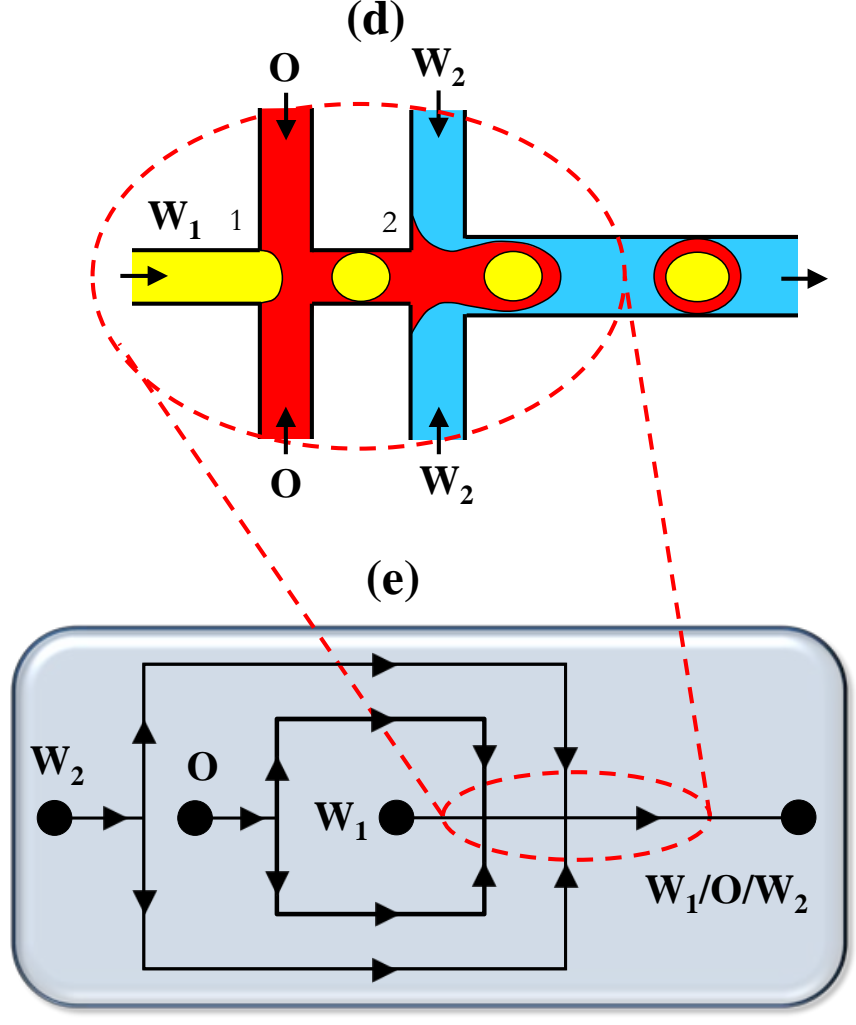

Figure 7. Production of core-shell drops on single planar chips with serial microfluidic junctions: (a) Two sequential T-junctions (Okushima et al., 2004; Nisisako et al., 2005); (b) Chip design for the process shown in (a); (c) Two sequential cross junctions with dripping instability present in junction 2 (Abate et al., 2011); (d) Two sequential cross junctions with dripping instability present in both junctions (Abate et al., 2011); (e) Chip design for the process shown in (c) and (d). Inlet and outlet ports are designated by the black circle ( $)$. 
(a) Countercurrent flow focusing

Pouring PDMS and curing

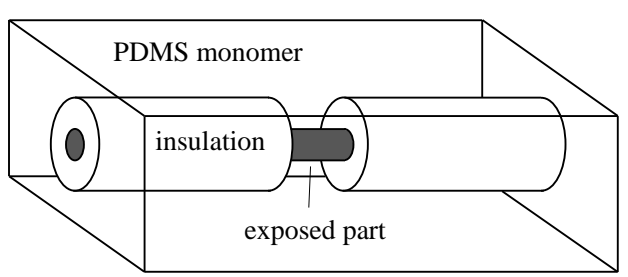

Removing optical fiber and inserting glass capillaries

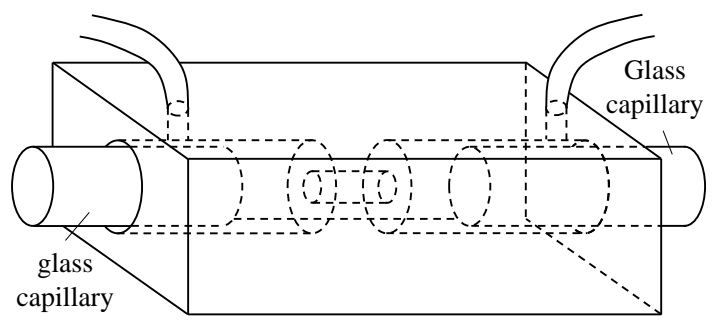

Drop generation by 3-D countercurrent flow focusing

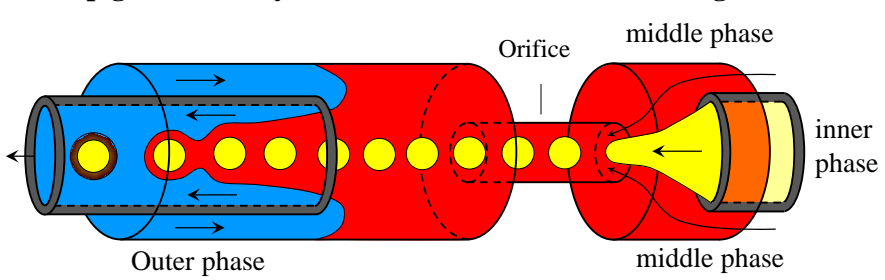

(b) Sequential cross-junctions

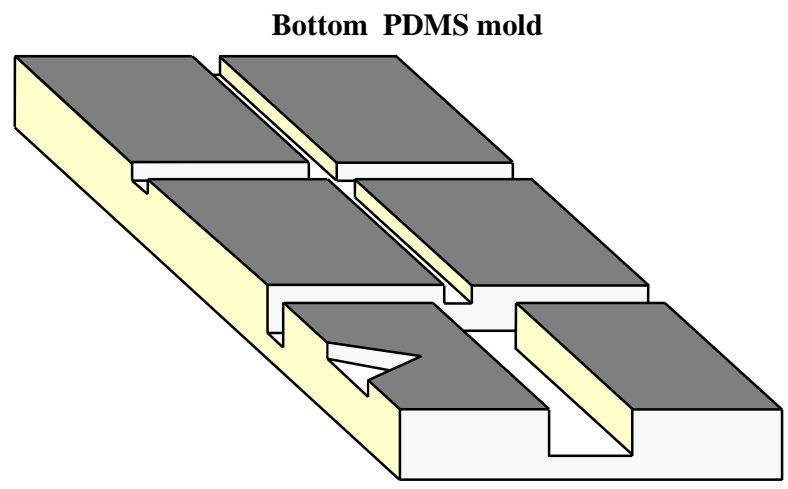

Assembled device with two PDMS molds bonded face to face

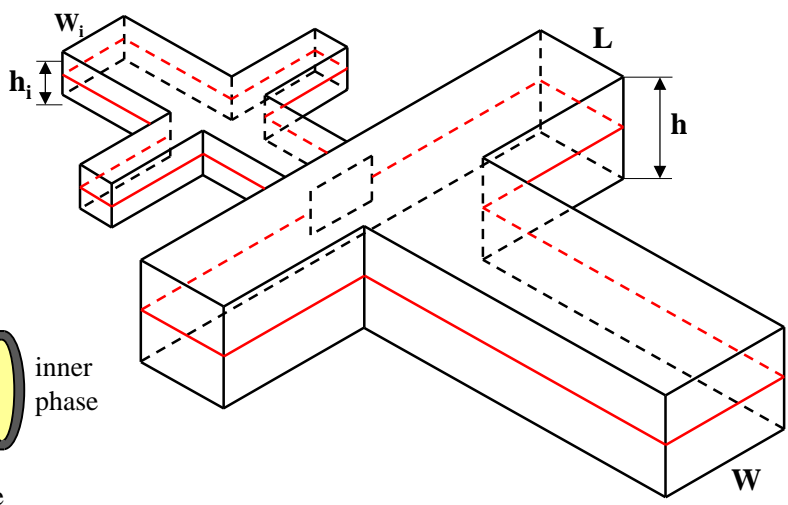

Figure 8. Non-planar microfluidic PDMS devices for making core-shell droplets: (a) Flow focusing device fabricated by embedding a microfiber in the mold before curing (Takeuchi et al., 2005); (b) Sequential cross junctions made by soft lithography using two complementary PDMS molds bonded face to face (Rotem et al., 2012). 
(a) Production of core/shell droplets with thick shells

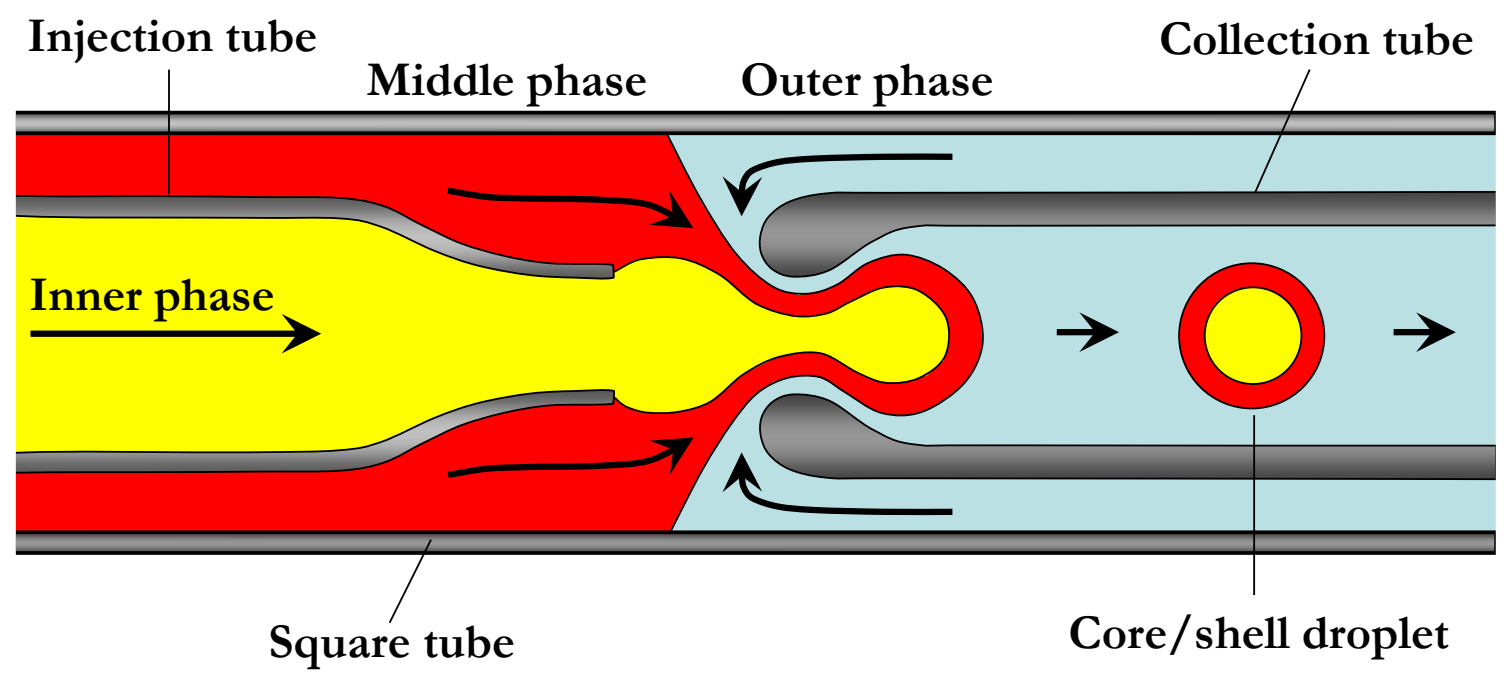

(b) Production of core/shell droplets with ultra-thin shells

Middle phase

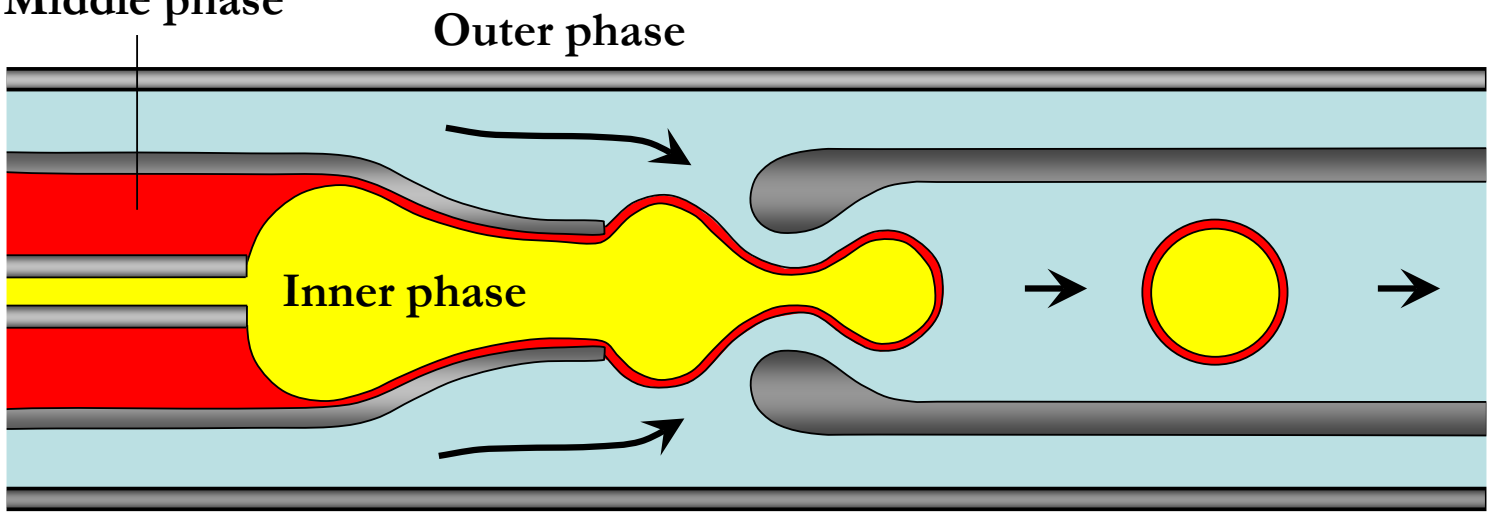

Figure 9. Production of core/shell droplets in glass capillary devices: (a) droplets with thick shells (Utada et al., 2005); (b) droplets with ultra-thin shells (Kim et al., 2011a; Datta et al., 2014). 
(a)
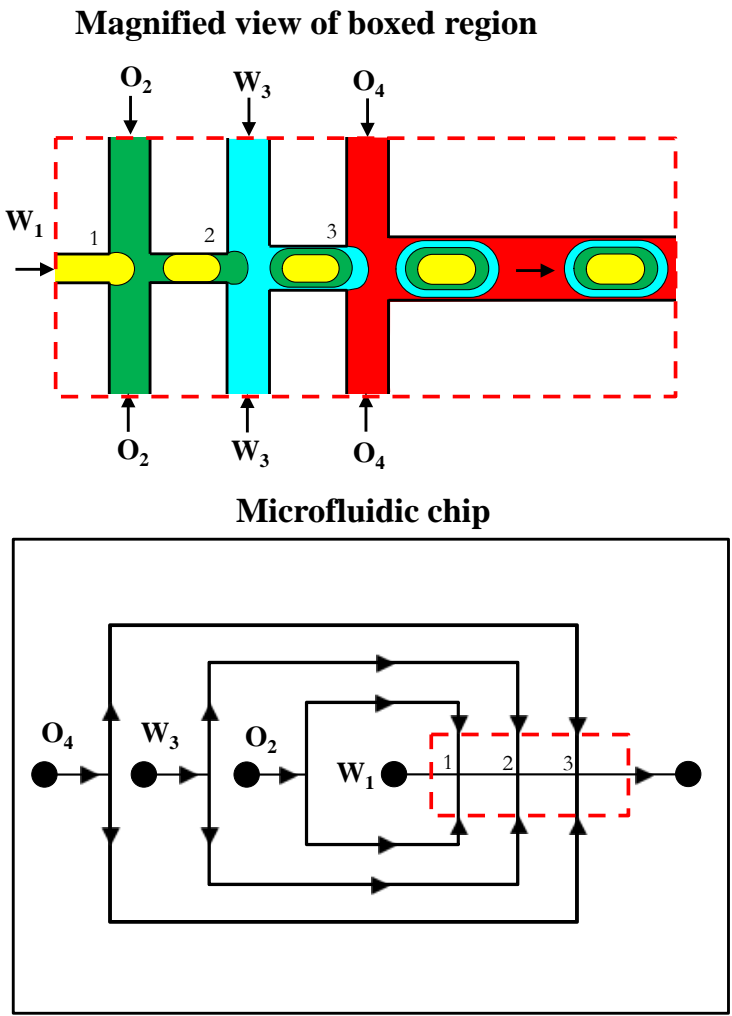

(b)

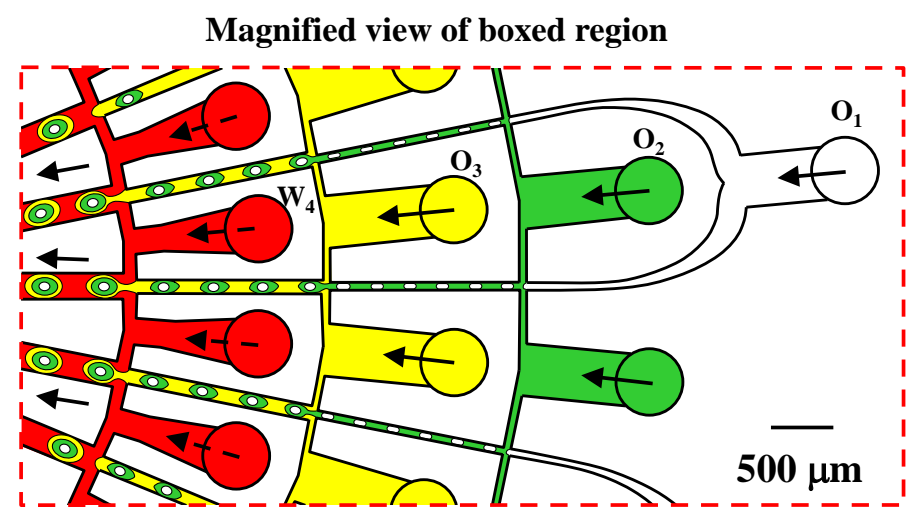

Microfluidic chip

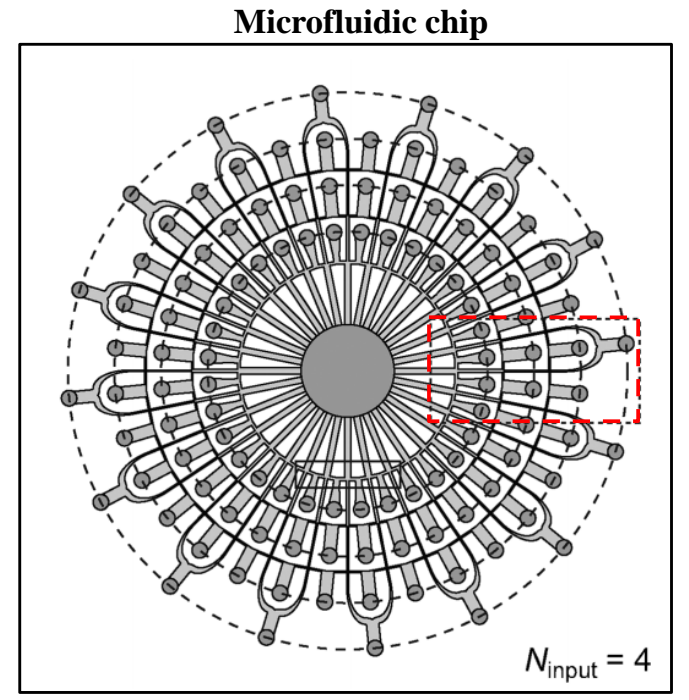

Figure 10. Microfluidic chips consisting of three sequential cross junctions for triple emulsions: (a) Production of $\mathrm{W}_{1} / \mathrm{O}_{2} / \mathrm{W}_{3} / \mathrm{O}_{4}$ emulsion in a PDMS chip containing one set of cross junctions with alternating wettability: junctions 1 and 3 are hydrophobic, whereas junction 2 is hydrophilic (Abate \& Weitz, 2009); (b) Production of $\mathrm{O}_{1} / \mathrm{O}_{2} / \mathrm{O}_{3} / \mathrm{W}_{4}$ emulsion in a glass chip containing 32 sets of cross junctions (96 junctions in total). The four dashed circles are the rings on which inlet holes for each fluid are placed. (Nisisako et al., 2012). The regions on both chips enclosed by the dashed red line are magnified. 
(a) Formation of triple emulsion with two coaxial injection tubes

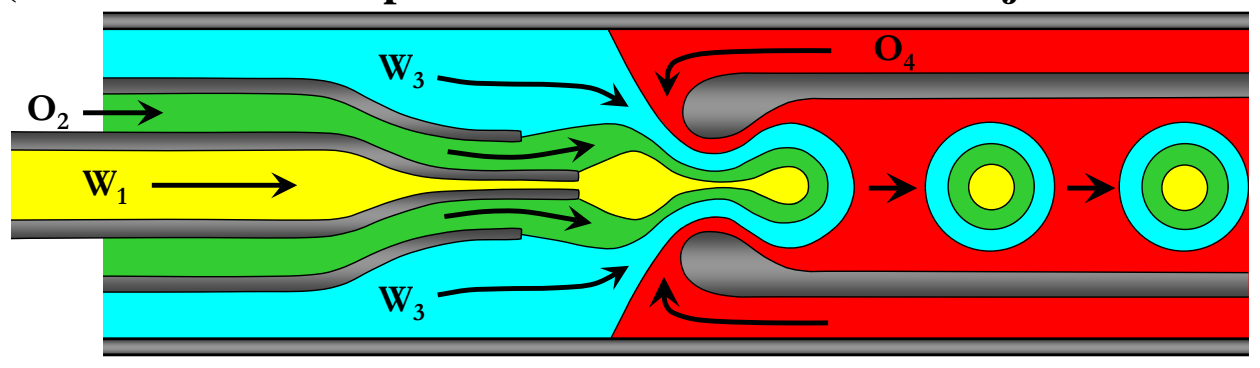

(b) Formation of triple emulsion using biphasic flow

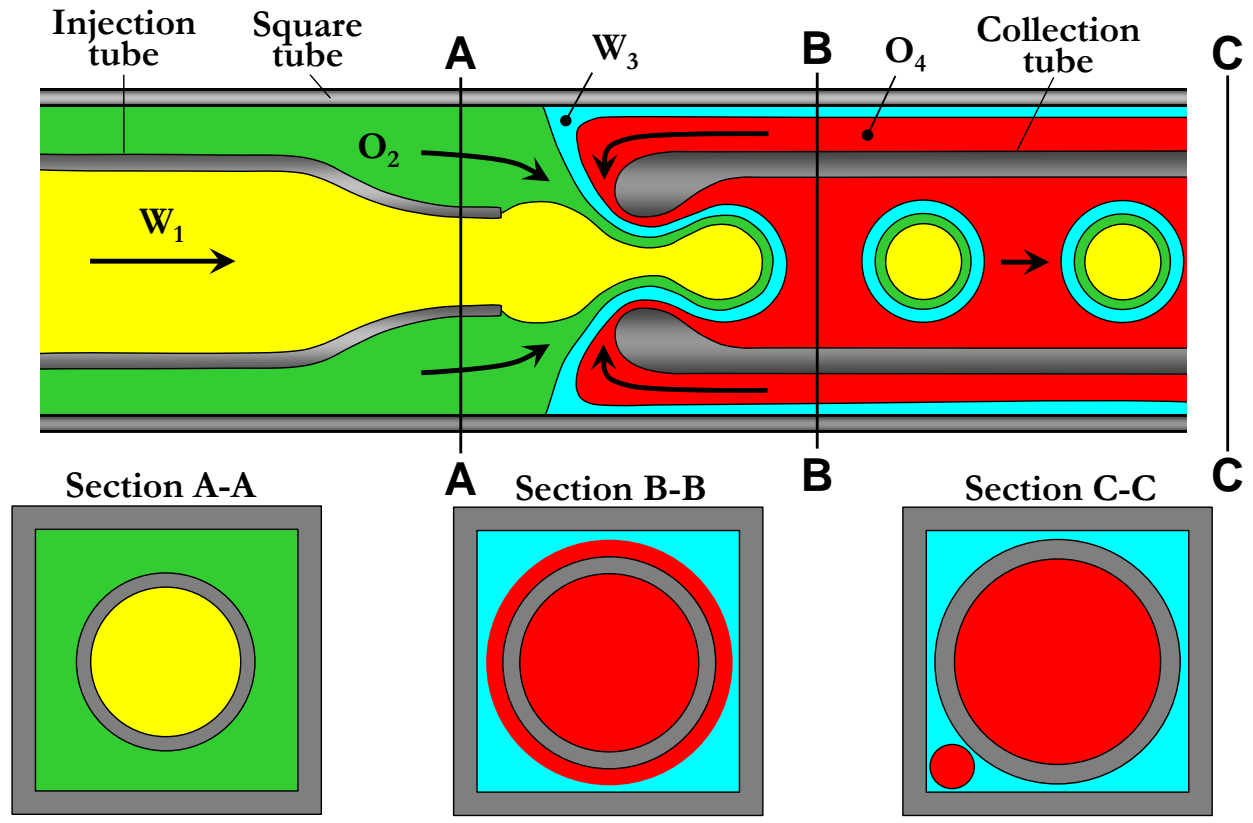

(c) Formation of quadruple emulsion using two biphasic streams

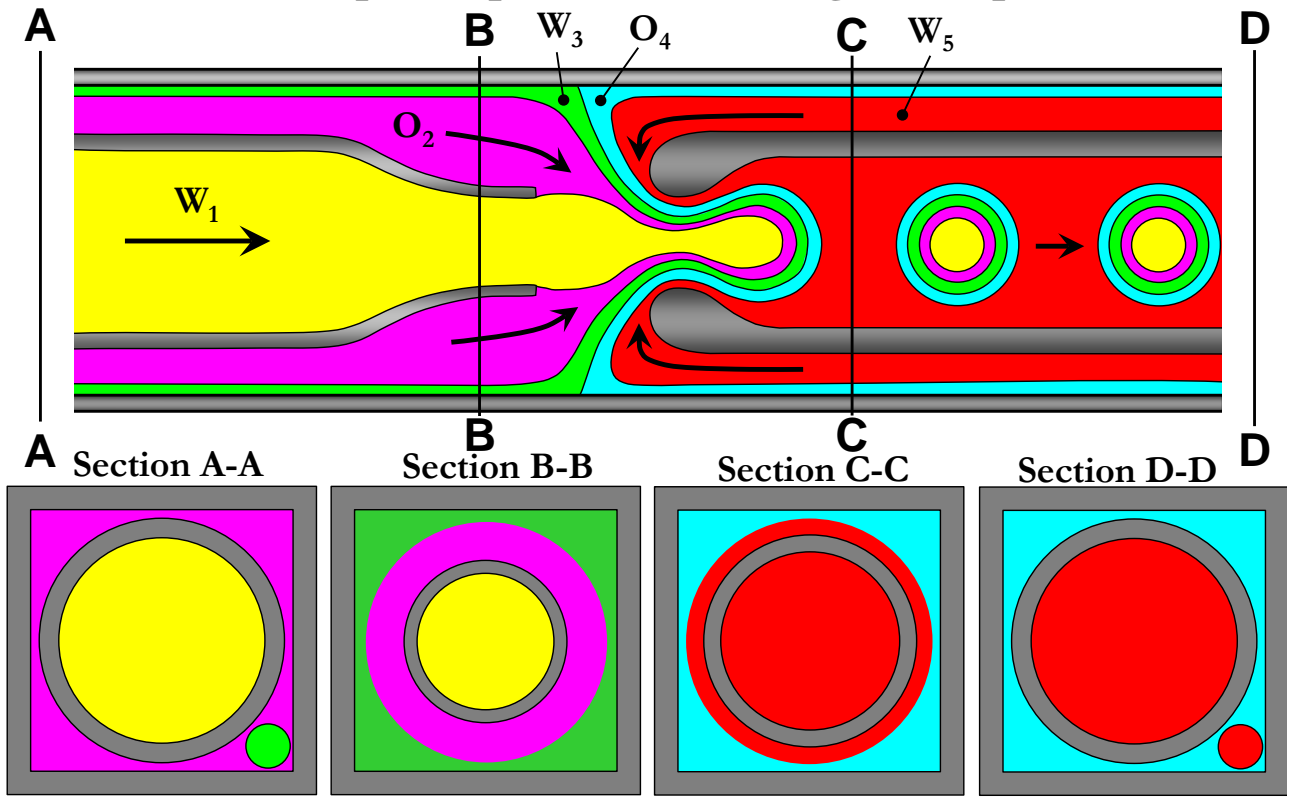

Figure 11. Forming drops with multiple concentric shells in glass capillary devices: (a) Triple $\mathrm{W}_{1} / \mathrm{O}_{2} / \mathrm{W}_{3} / \mathrm{O}_{4}$ emulsion formed using coaxial injection tubes (Utada et al., 2005); (b) Triple $\mathrm{W}_{1} / \mathrm{O}_{2} / \mathrm{W}_{3} / \mathrm{O}_{4}$ emulsion formed using biphasic flow (Kim \& Weitz, 2011); (c) Quadruple $\mathrm{W}_{1} / \mathrm{O}_{2} / \mathrm{W}_{3} / \mathrm{O}_{4} / \mathrm{W}_{5}$ emulsion formed using two biphasic streams (Kim \& Weitz, 2011). 
(a) One-step emulsification with jetting of middle phase
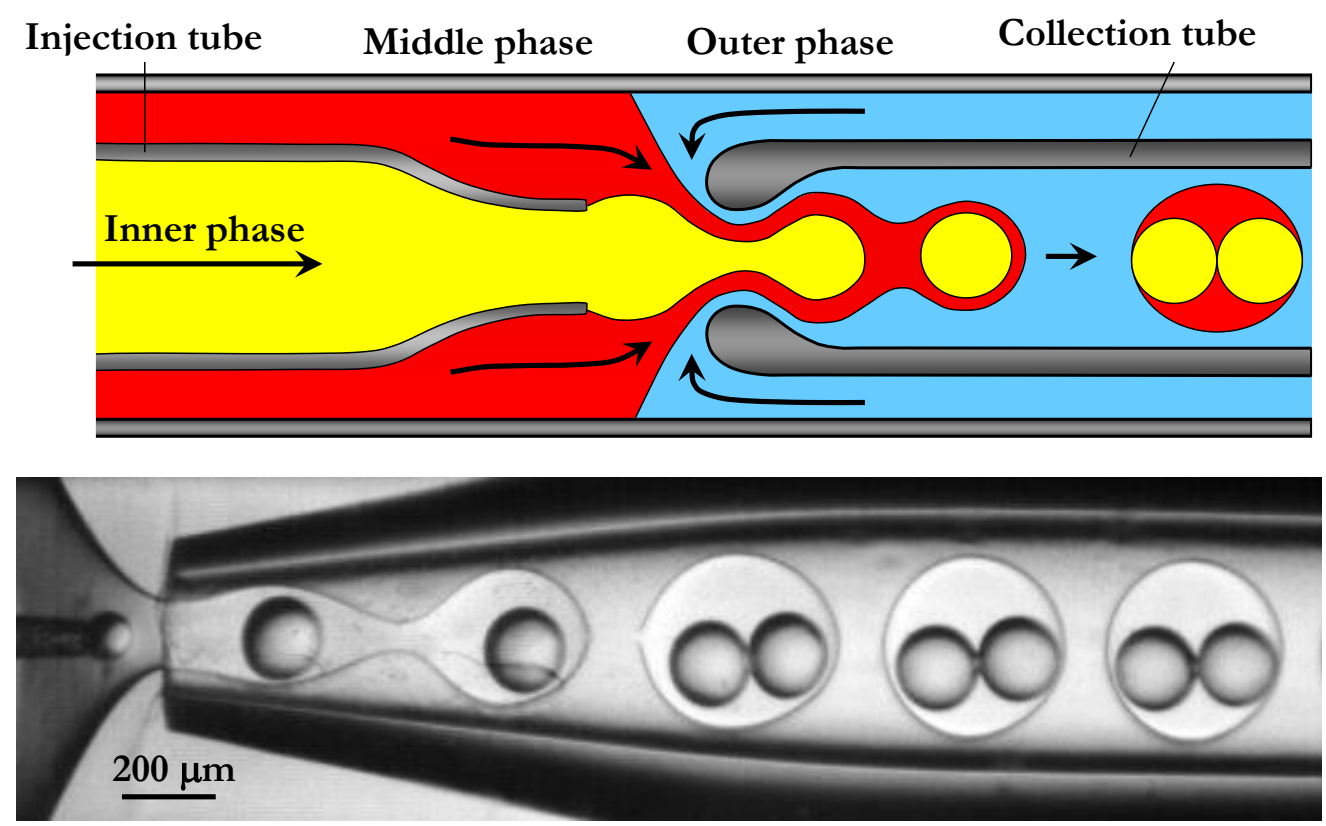

(b) Two-step emulsification in co-flowing streams

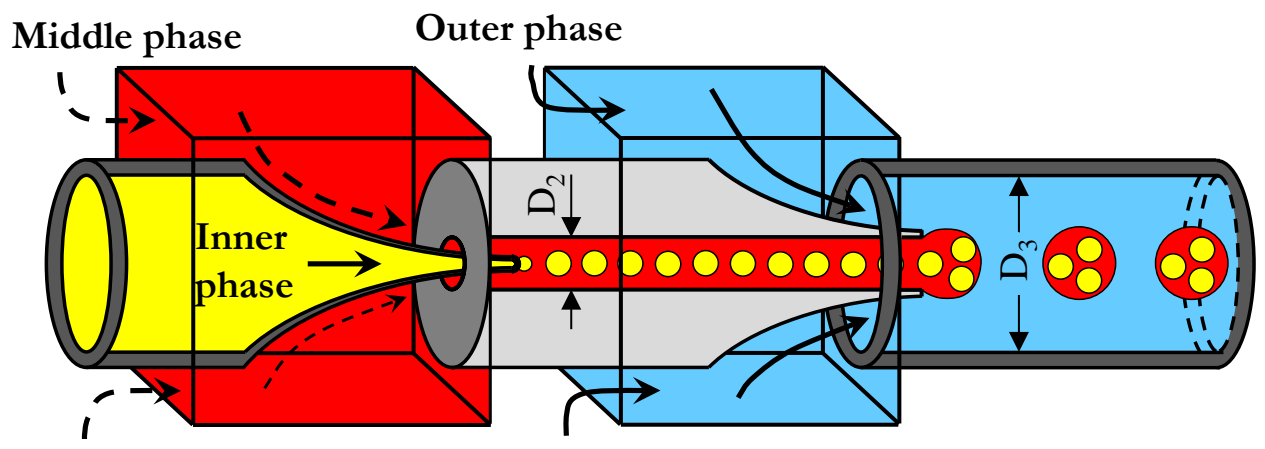

Figure 12. Forming drops with a controlled number of inner drops in glass capillary devices: (a) One-step emulsification by combining co-flow and flow focusing in the dripping-to-jetting transition regime; (b) Two-step emulsification using two sequential co-flow drop makers (Chu et al., 2007). 
Middle phase 1 at $\mathbf{Q}_{2} \quad$ Middle phase 2 at $\mathbf{Q}_{3} \quad$ Outer phase at $\mathbf{Q}_{4}$

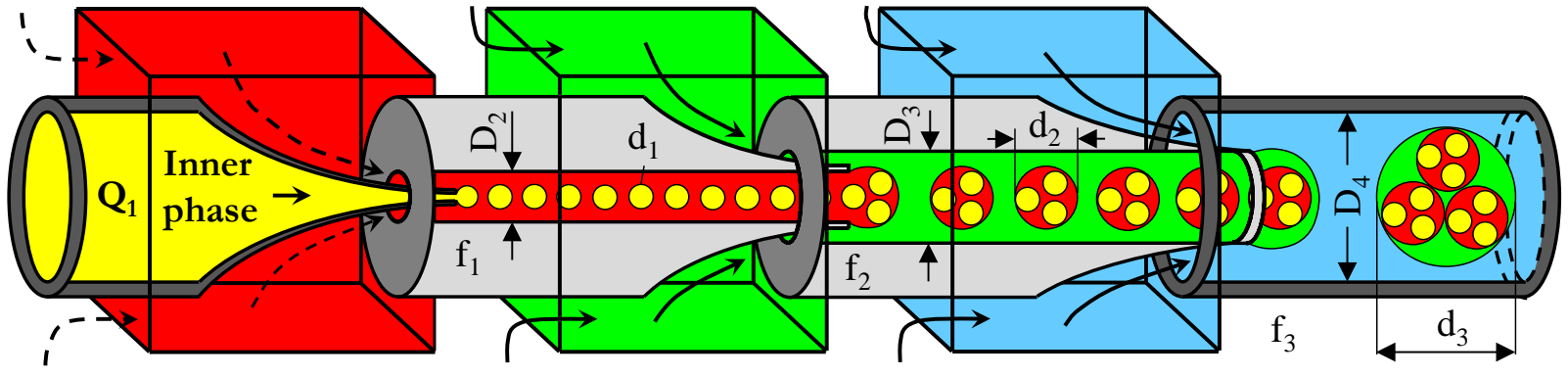

Figure 13. Production of triple emulsions using glass capillary device with three sequential co-flow drop formation stages (Chu et al., 2007). 


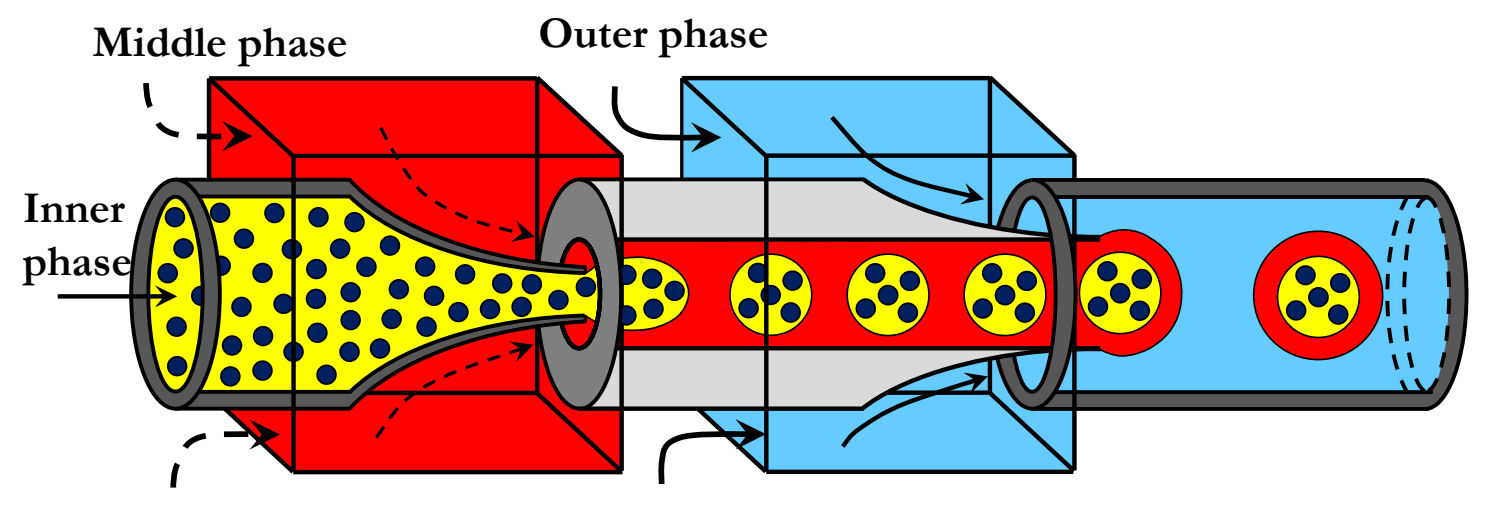

Figure 14. Fabrication of triple emulsion drops with an outer shell and numerous inner droplets dispersed in the middle phase. Glass capillary device was used with two sequential co-flow drop generation stages (Liu et al., 2010). 
(a) Two consecutive junctions

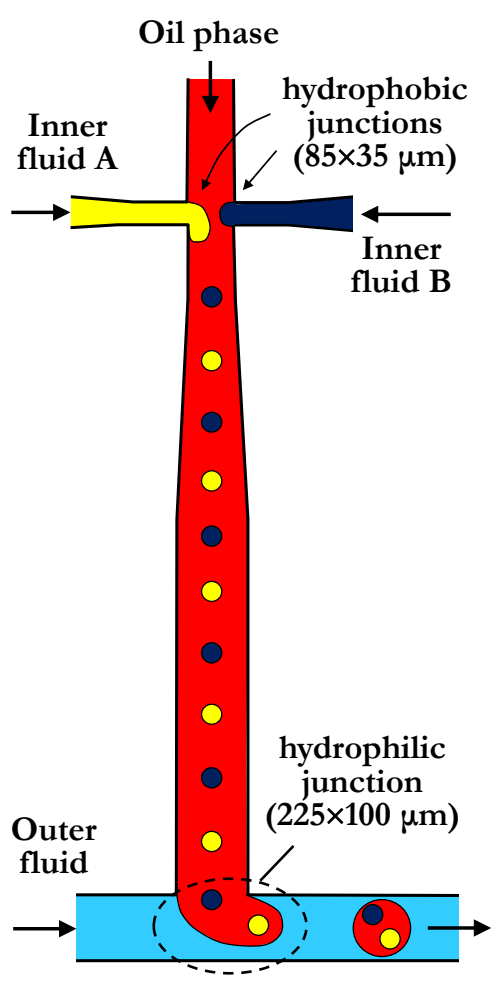

(b) Flow focusing device with two-bore injection tube

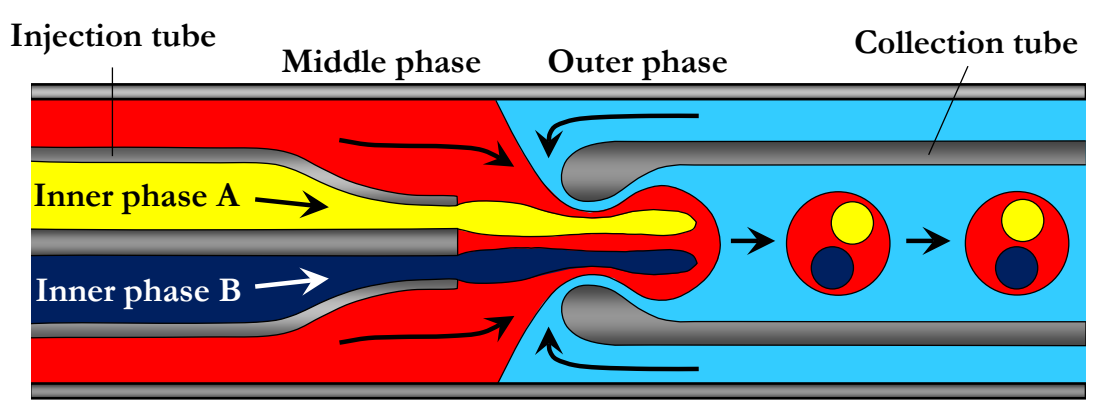

(c) Array of parallel capillaries in co-flowing streams

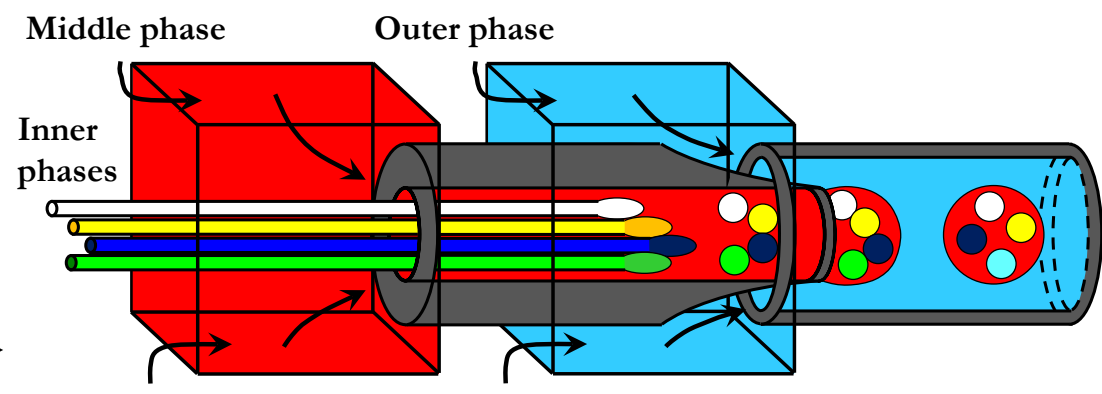

Figure 15. Production of W/O/W emulsions with distinct internal droplets: (a) Planar chip with one upstream cross-junction and one downstream T junction (Okushima et al., 2004); (b) Flow focusing glass-capillary device with dual-bore injection tube (Sun et al., 2010); (c) Coflow glass capillary device with an array of four parallel injection tubes (Zhao et al., 2012). 
(a)

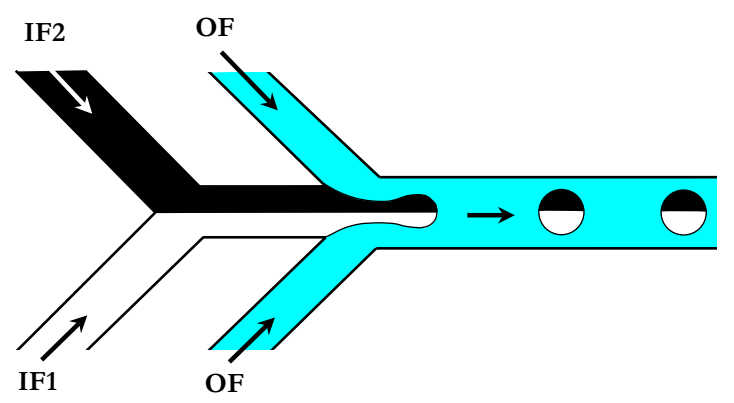

(b)

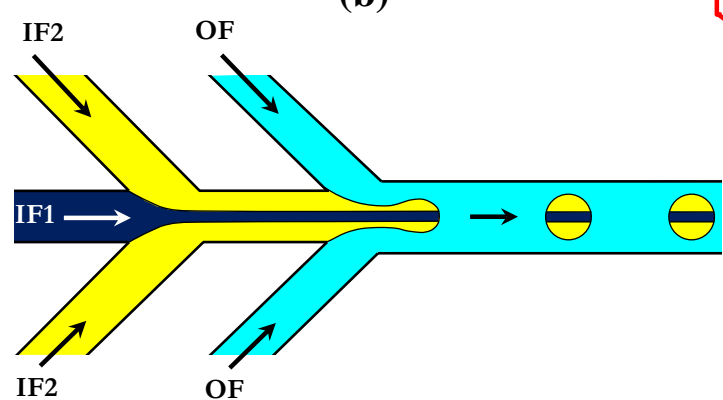

(c)

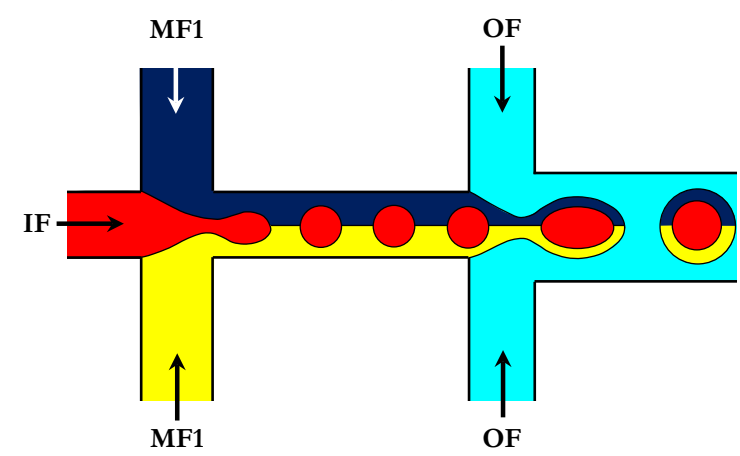

(d)

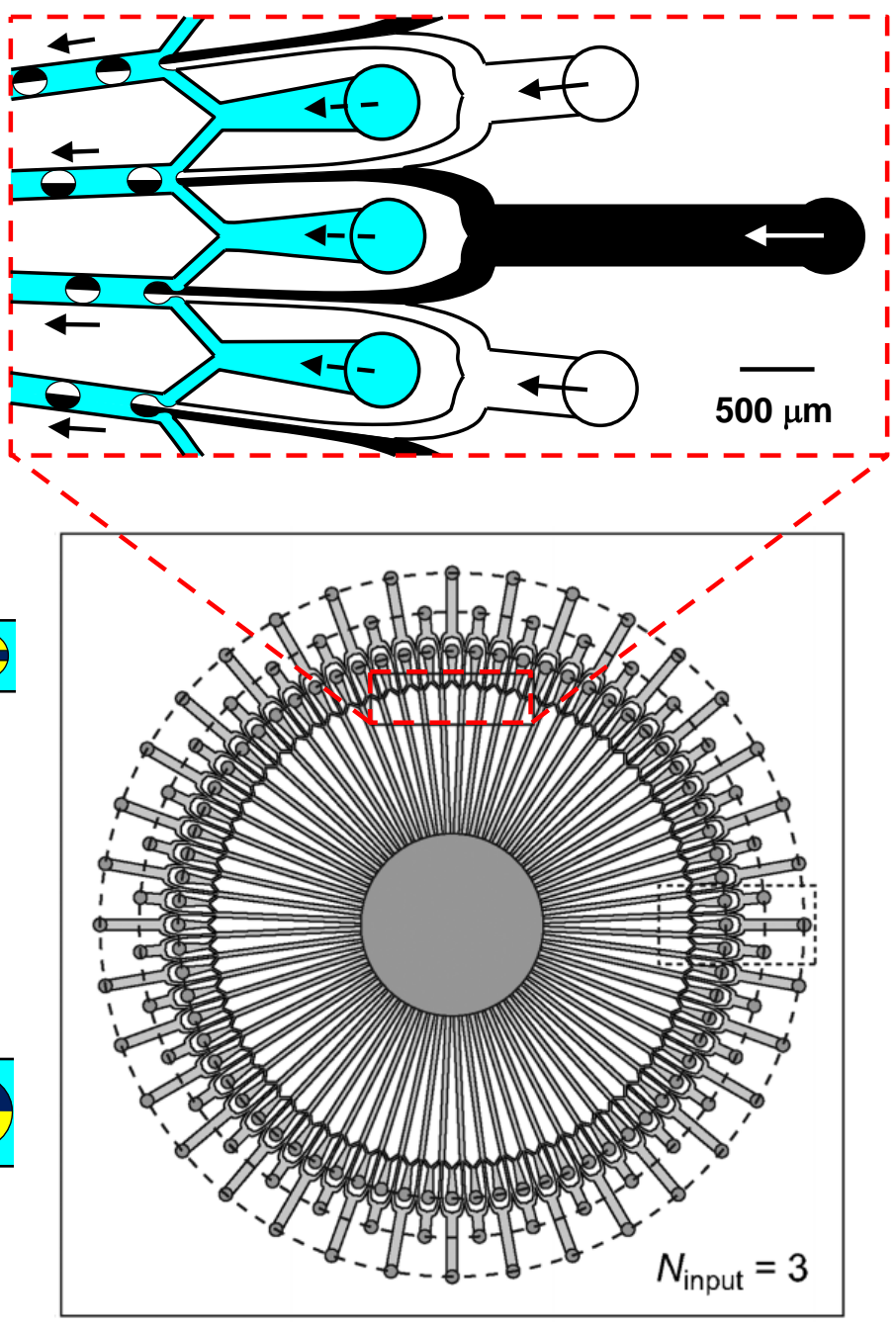

Figure 16. (a) Production of Janus drops by integration of Y-junction and cross junction (Nisisako et al., 2006); (b) Production of ternary drops using two sequential flow focusing drop generators (Nisisako et al., 2014); (c) Production of core/shell drops with Janus shells using two sequential cross junctions (Seiffert et al., 2010); (d) High-volume production of Janus drops using 72 droplet generation units with inlet ports for the three phases placed on three concentric circles (Nisisako et al., 2012). The red dashed box indicates the magnified region (IF - inner fluid, MF - middle fluid, OF - outer fluid). 